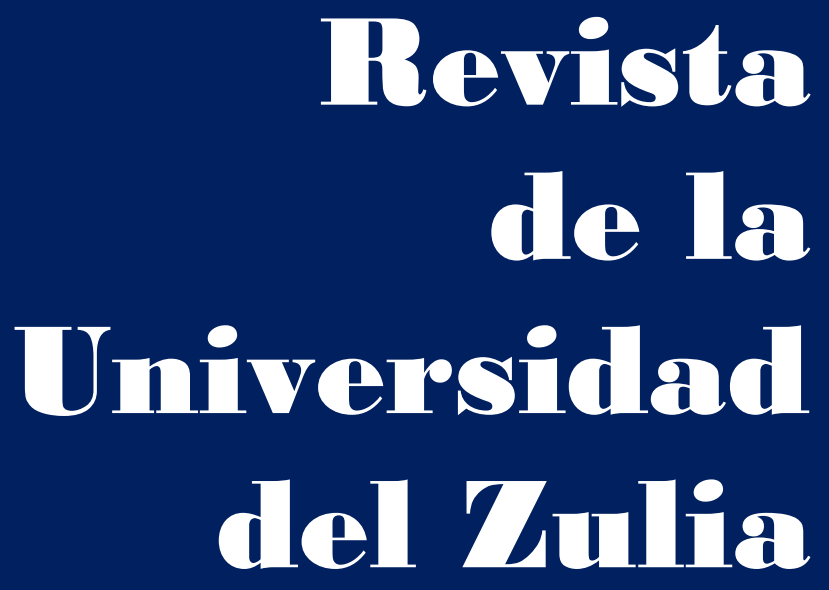

Fundada en 1947

por el Dr. Jesús Enrique Lossada

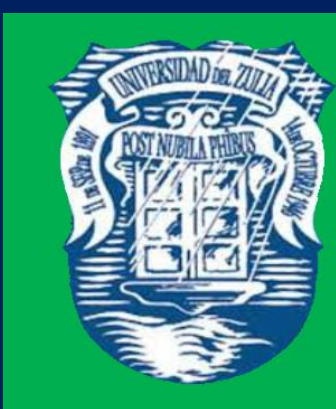

Ciencias del

Agred

Ingemieria

y Teenología
Añต 12 No 32

Enero - Abril 2021

Tercera Época

Maracailbo-Venezuela 


\title{
Análisis crítico del potencial del plasma frío como tecnología no destructiva en el procesamiento alimentario: situación actual y tendencias futuras
}

\author{
Vicente Tirado-Kulieva* \\ William Rolando Miranda Zamora** \\ Nelly Luz Leyva Povis***
}

RESUMEN

El Plasma frío surge como una tecnología no térmica con distintas aplicaciones en los alimentos, con un mínimo efecto en su calidad. El objetivo de esta revisión fue analizar su potencial no destructivo en la mencionada industria, para la cual, se recopiló información de libros y artículos científicos de alto impacto, especialmente de los últimos años y fue estructurada enfatizando, la conservación alimentaria y otros campos del procesamiento. De acuerdo a las investigaciones consultadas, el plasma frío ha mostrado eficacia en la descontaminación microbiana e inactivación enzimática, en la mejora de las características sensoriales y fisicoquímicas de los alimentos, en la funcionalización del sistema de envasado y también en el tratamiento de aguas residuales generadas. El mecanismo de acción se basa en sus especies reactivas que, al tener contacto con los microorganismos y enzimas, los afecta hasta su muerte y degradación, respectivamente. En la interacción con los compuestos como el almidón, estas especies inducen en una mejora funcional significativa y preservan los termosensibles como las vitaminas. De igual manera ocurre con la carga microbiana y química de las aguas residuales, logrando su purificación. A pesar del enorme potencial detallado, al ser una tecnología relativamente nueva, se requiere de mayor investigación para suplir sus limitaciones, además de evaluar su uso sinérgicamente con otras técnicas para mejorar el proceso y sus resultados.

PALABRAS CLAVE: Innovación; procesamiento de alimentos; seguridad alimenticia; agricultura; hortalizas; agua residual

*Universidad Nacional de Frontera, Sullana, Perú. ORCID: https:/orcid.org/0000-0001$8534-9153$

**Docente Investigador. Universidad Nacional de Frontera, Sullana. Perú. ORCID: https://orcid.org/0000-0002-0829-2568

***Docente Asociada. Universidad Nacional de Piura. Perú. ORCID: https://orcid.org/00000003-1821-1044

Recibido: 30/10/2020

Aceptado: 17/12/2020 


\section{Critical analysis of the potential of cold plasma as a non- destructive technology in food processing: current situation and future trends}

ABSTRACT

Cold plasma emerges as a non-thermal technology with different applications in food, with a minimal effect on its quality. The objective of this review was to analize its non-destructive potential in the mentioned industry, for which information was collected from books and scientific articles of high impact, especially from the last years and it was structured enphasizing food preservation and other processing fields. According to the consulted researches, cold plasma has shown efficacy in microbial decontamination and enzymatic inactivation, in the improvement of sensory and physicochemical characteristics of food, in the functionalization of the packaging system and also in the treatment of generated wastewater. The mechanism of action is base don its reactive species which, when in contact with microorganisms and enzymes, affects them ultil their death and degradation, respectively. In the interaction with compounds such as starch, these species induce a significant functional improvement and preserve heat-sensitive compounds such as vitamins. The same occurs with the microbial and chemical load of wastewater, achieving its purification. Despite the enormous detailed potential, being a relatively new technology, further research is required to address its limitations, as well as to evaluate its use synergistically with other techniques to improve the process and results.

KEYWORDS: Innovation; food processing; food security; agriculture; vegetables; waste water.

Introducción

En la actualidad, la industria de alimentos tiene problemas asociados con la higiene y calidad alimentaria (Hati et al., 2018; Misra et al., 2018), siendo la sostenibilidad alimentaria, uno de los más preocupantes (Feizollahi et al., 2020; Fellows, 2016) y debido a eso, los consumidores al estar más preocupados por su salud, buscan alimentos seguros y que cumplan con los criterios de calidad (Baggio et al., 2020; Lacombe et al., 2015; Niemira y sites, 2008; Pinela y Ferreira, 2015), pero a pesar de ello, las enfermedades de transmisión alimentaria (ETAs) continúan siendo un reto, las cuales son ocasionadas por alimentos en mal estado por especialmente acción de microorganismos (MO) patógenos y de descomposición (Bermúdez-Aguirre et al., 2013; Liao et al., 2017; Niemira, 2012; Pan et al., 2019a; Stoica et al., 2014), y enzimas naturales que también pueden causar su deterioro; 


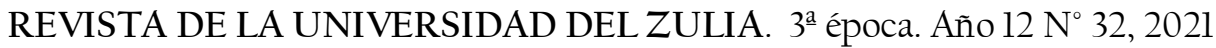

Vicente Tirado-Kulieva et al. // Análisis crítico del potencial del plasma frío como tecnología ...284-316

DOI: http://dx.doi.org/10.46925//rdluz.32.18

repercutiendo de manera general en términos económicos y en la salud pública (Niemira, 2012; Ziuzina et al., 2014). Cabe destacar que esto afecta principalmente a las frutas, verduras (Niemira y sites, 2008), carnes y demás alimentos frescos que, al no ser procesados o sí, pero mínimamente, son más susceptibles y tienen una vida útil limitada (Liao et al., 2020; Pan et al., 2019b).

Considerando lo previo, para obtener alimentos en óptimas condiciones, naturales, nutritivos, atractivos, sabrosos e inocuos sin el empleo de conservantes y demás aditivos químicos (Bermúdez-Aguirre et al., 2013; Scholtz et al., 2015; Surowzky et al., 2014), se emplean diversos métodos de conservación para reducir o eliminar la carga microbiana en el alimento y de igual manera con las alteraciones bioquímicas, logrando prolongar su vida de anaquel (Fellows, 2016). Existen las tecnologías térmicas tradicionales que se han usado por largo tiempo (Kaluwahandi et al., 2020) como la pasteurización, esterilización, calentamiento óhmico, etc. (Niemira, 2012; Ziuzina et al., 2014), que, aunque sean eficientes en la inhibición microbiológica y enzimática, suelen afectar las características sensoriales, fisicoquímicas y nutricionales por la termosensibilidad de muchos compuestos que contienen los alimentos (Alves et al., 2020; Liao et al., 2017; Pinela y Ferreira, 2015; Scholtz et al., 2015). A causa de ello, con el fin de evitar el daño al alimento (Chizoba et al., 2017), también existen las tecnologías no térmicas como el procesamiento a altas presiones, la irradiación, el campo eléctrico pulsado, luz pulsada, luz ultravioleta (UV), ultrasonido, la aplicación de ozono, entre otras (Baier et al., 2014; Kaluwahandi et al., 2020; Niemira, 2012; Pan et al., 2019b; Ziuzina et al., 2014), que también ofrecen sus respectivas ventajas y con buenos resultados, pero no logran reemplazar en su totalidad a las térmicas.

Para satisfacer la necesidad de aplicar tecnologías de conservación a bajas temperaturas que sean igual de eficaces que las térmicas convencionales, se están investigando nuevas alternativas o procesos complementarios a los comunes (Mandal et al., 2018; Misra et al., 2014) como el congelamiento y la refrigeración (Pan et al., 2019a; Pankaj et al., 2014), para garantizar la inocuidad alimentaria y conservar la mayor parte de sus características y propiedades (Liao et al., 2020). En la última década, el plasma frío (PF) está atrayendo cada vez más la atención al ser una tecnología no térmica prometedora (Chizoba et al., 2017; Feizollahi et al., 2020; Sonawane et al., 2020; Thirumdas et al., 2017) que causa un nulo o mínimo impacto en los atributos de los alimentos tratados (Hati et al., 2018; Pankaj et 


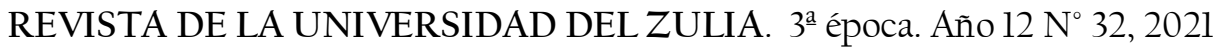

Vicente Tirado-Kulieva et al. // Análisis crítico del potencial del plasma frío como tecnología ...284-316

DOI: http://dx.doi.org/10.46925//rdluz.32.18

al., 2018; Sarangapani et al., 2018; Stoica et al., 2014), evitando cambios en la composición como la desnaturalización de las proteínas, el pardeamiento enzimático o no enzimático, pérdida de vitaminas, cambios en las características sensoriales (olor, color, sabor, textura), entre otras (Coutinho et al., 2018; Pan et al., 2019b), además de requerir bajos niveles de energía (Alkawareek et al., 2014; Patil et al., 2016; Sonawane et al., 2020) y ofrecer un tiempo de procesamiento muy corto (Alves et al., 2020).

El PF es una tecnología emergente económica, versátil y amigable con el ambiente (Charoux et al., 2020; Gavahian et al., 2018; Han et al., 2019; Pankaj et al., 2014; Pankaj et al., 2018) que se ha empleado principalmente como descontaminante en la industria médica, electrónica y textil (Niemira, 2012; Pankaj et al., 2014), debido a su enorme potencial antimicrobiano (Feizollahi et al., 2020) y por ello, además ha empezado a utilizarse en la desinfección/esterilización de una gran variedad de alimentos (Chizoba et al., 2017; Pinela y Ferreira, 2015), incluyendo la de sus empaques (Hati et al, 2018; Pankaj et al., 2014; Pankaj y Keener, 2017), además de múltiples aplicaciones, aprovechando sus distintas propiedades químicas.

Por lo tanto, esta revisión es la recopilación de los últimos estudios acerca de la tecnología del PF y su aplicación en la industria alimentaria. A pesar de ser poco estudiada, el PF abarca un gran campo de aplicación en la mencionada industria. Se tendrá como visión general los fundamentos del plasma y obtención del PF y como enfoque principal, su uso como técnica antimicrobiana, inactivador enzimático, su efecto en la calidad alimentaria, en envases y recubrimientos comestibles y, además, en la descontaminación de aguas residuales, con sus respectivos mecanismos de acción.

\section{Materiales y Métodos}

Para la presente revisión, se realizó la búsqueda de información de manera exhaustiva y concisa de fuentes fidedignas en relación a la materia de estudio, el plasma frío y su aplicación en la industria alimentaria. Las fuentes consultadas incluyen libros y especialmente artículos científicos, los cuales fueron seleccionados a partir de revistas reconocidas a nivel internacional, principalmente las de alto impacto indexados en Scopus y Web of Science. Se priorizó la información más reciente, representando más del 65\% la de los últimos cinco años para poder tener una visión más amplia y precisa de las últimas 


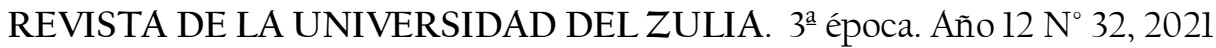

Vicente Tirado-Kulieva et al. // Análisis crítico del potencial del plasma frío como tecnología ...284-316

DOI: http://dx.doi.org/10.46925//rdluz.32.18

investigaciones. Asimismo, la estructuración del estudio se realizó de forma entendible, diseñando tablas y figuras para una mejor comprensión del tema.

2. Fundamentos del Plasma Frío

2.1. Principios del plasma: fuentes y química

El plasma, debido a sus propiedades únicas, es denominado como el cuarto estado de la materia (Baggio et al., 2020; Bourke et al., 2017; Fridman, 2008; Misra et al., 2011). Es un gas ionizado (mediante la aplicación de energía) de forma total o parcial, compuesto por especies reactivas (ER) como iones, electrones y átomos, moléculas y radicales libres (Charoux et al., 2020; Chizoba et al., 2017; Kaluwahandi et al., 2020; Mandal et al., 2018; Mir et al., 2020; Niemira, 2012) en el que se producen múltiples reacciones químicas y radiación electromagnética como la luz visible y la UV (Bao et al., 2020a; Chen et al., 2019; Schlüter et al., 2013). Se considera que el plasma es un gas eléctricamente neutro (Lieberman y Lichtenberg, 2005; Misra et al., 2011; Ozen y Singh, 2020) ya que la densidad de cargas positivas y negativas, es la misma (Charoux et al., 2020; Munekata et al., 2020; Niemira, 2014). Además, es visualizado como una descarga de luz fluorescente brillante (Niemira, 2012; Stoica et al., 2014).

Puede ser obtenido utilizando diversas fuentes de energía como descargas de barreras dieléctricas (DBD), descargas de corona (DC), descarga de arco eléctrico (DAE), arco de deslizamiento (AD), chorro de plasma (CP), aguja de plasma (AP), radiofrecuencias (RF), radiación de calor (RC), microondas (MO) y fotoionización (FI) (Hati et al., 2018; Liao et al., 2017; Lieberman y Lichtenberg, 2005; Mir et al., 2020; Misra et al., 2014; Munekata et al., 2020, Niemira, 2012; Ozen y Singh, 2020; Pan et al., 2019a; Sarangapani et al., 2018).

Chizoba et al. (2017); Fridman (2008) indican que, durante la generación del plasma, además de la ionización, ocurren otras reacciones químicas como la excitación, desexcitación, disociaciones, fragmentaciones, etc. y de acuerdo a Scholtz et al. (2015); Thirumdas et al. (2017), su química se ve influenciada de factores como la composición del gas usado, la humedad, la temperatura, la potencia, voltaje y fuente usada (Figura 1).

Niemira (2012) menciona que, el gas a ionizar puede ser aire, moléculas como el oxígeno $\left(\mathrm{O}_{2}\right)$, dióxido de carbono $\left(\mathrm{CO}_{2}\right)$, nitrógeno $\left(\mathrm{N}_{2}\right)$ o una mezcla que contenga gases nobles como el Argón (Ar), Helio (He) o Neón (Ne). Munekata et al. (2020); Niemira (2014) 
señalan que estos carecen de estructura hasta que se les aplica la energía necesaria para que se rompan, liberando electrones, iones libres, etc. Las ER obtenidas más comunes de acuerdo a los factores previamente vistos, son según Ji et al. (2020); Schlüter et al. (2013); Scholtz et al. (2015); Thirumdas et al. (2017) las ER de oxígeno (ERO) como el oxígeno atómico (O), el molecular o singlete $\left(\mathrm{O}_{2}\right)$, el anión superóxido $\left(\mathrm{O}_{2}^{-}\right)$, el ozono $\left(\mathrm{O}_{3}\right)$ y el radical hidroxilo $(\mathrm{OH})$; las ER de nitrógeno (ERN), como el ión $\mathrm{N}_{2}^{+}$, el óxido nítrico (NO) y el peroxinitrito (ONOO' ); diferentes formas de óxido de nitrógeno (NxOy), y luz UV. Si existen altos niveles de humedad, pueden generarse especies como el anión $\mathrm{H}^{\prime}$, el ión $\mathrm{H}_{2} \mathrm{O}^{+}$, el hidronio $\mathrm{H}_{3} \mathrm{O}^{+}$, el anión hidróxido $\left(\mathrm{OH}^{-}\right)$, el peróxido de hidrógeno $\left(\mathrm{H}_{2} \mathrm{O}_{2}\right)$ y demás especies con o sin excitación. Como se aprecia, las especies predominantes varían especialmente por el gas utilizado.

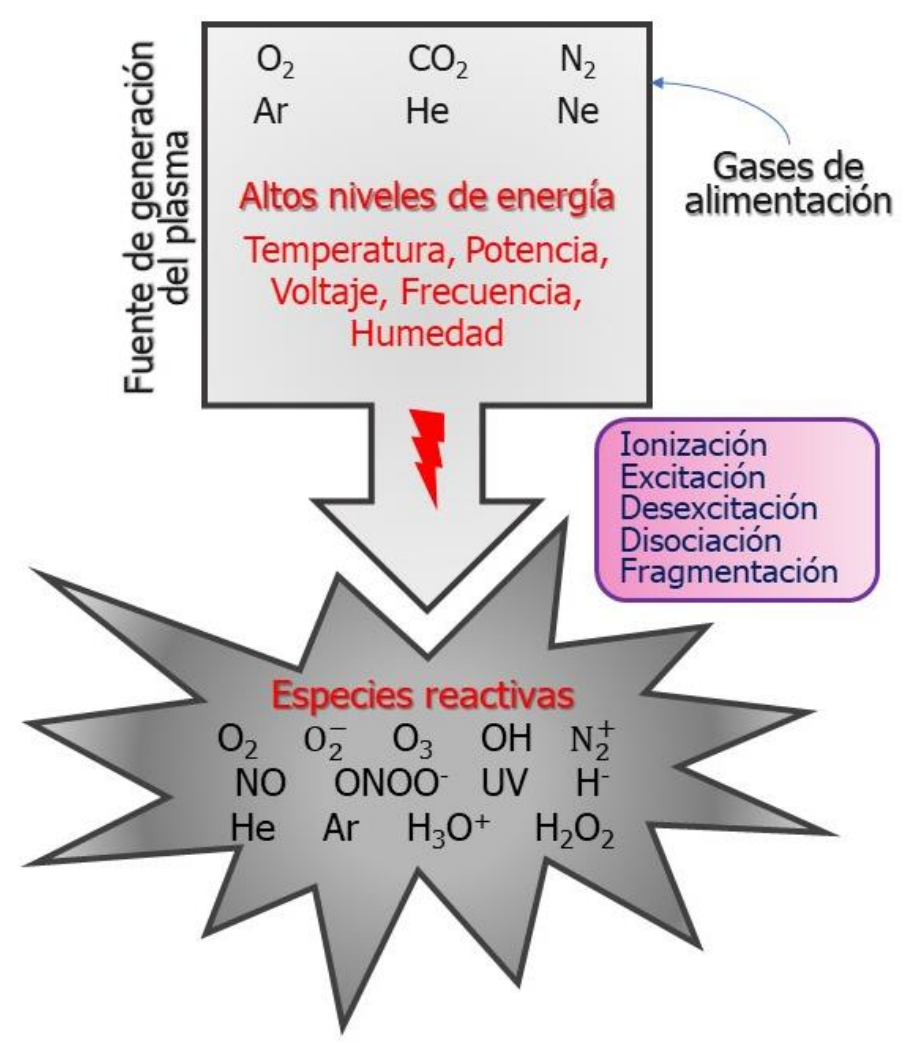

Figura 1. Proceso de generación de plasma: gases empleados, parámetros de operación, reacciones químicas ocurridas y especies reactivas generadas.

\subsection{Tipos de plasma}

En función de la temperatura y/o condiciones en las que se genera, se distinguen dos tipos de plasma, el térmico y el no térmico (Baggio et al., 2020; Chen et al., 2019; Misra et al., 2011; Scholtz et al., 2015). 


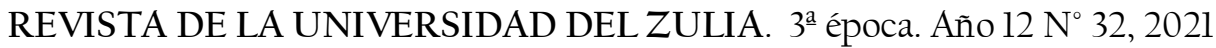

Vicente Tirado-Kulieva et al. // Análisis crítico del potencial del plasma frío como tecnología ...284-316

DOI: http://dx.doi.org/10.46925//rdluz.32.18

Scholtz et al. (2015) explican que, para originar el plasma térmico, se necesitan niveles extremos de presión ( $\geq 105$ Pascal $(\mathrm{Pa})$ ) y potencia (hasta 50 Megawatts (MW)), aplicándose, según Chen et al. (2019) en industrias como la metalúrgica y aeronáutica. Chen et al. (2019); Charoux et al. (2020); Misra et al. (2016); Scholz et al. (2015) afirman que tiene un equilibrio termodinámico en su sistema, al mantener la temperatura de manera uniforme entre los electrones y demás especies. Schlüter et al. (2013) mencionan que un ejemplo de plasma térmico podría ser una antorcha de plasma.

A diferencia del plasma térmico en la que la temperatura de los electrones (Te) oscila entre $10^{4}-10^{8} \mathrm{~K}$, el del plasma no térmico está entre $300 \mathrm{~K}$, pudiendo alcanzar hasta $10^{4} \mathrm{~K}$ (Han et al., 2019). Este último, el PF o también llamado plasma de baja temperatura (30 - 60 ${ }^{\circ}$ C) (Kaluwahandi et al., 2020; Misra et al., 2011; Stoica et al., 2014) se puede generar a presiones que varíen entre $<1 \mathrm{~Pa}$, hasta $100 \mathrm{~Pa}$, siendo el PF de baja presión o también a 101,325 $\mathrm{Pa}$, considerado como el PF atmosférico (PFA). El PF es un "plasma de desequilibrio" ya que la Te es mayor a la temperatura de los iones (Charoux et al., 2020; Schlüter et al., 2013; Thirumdas et al., 2015) y como la temperatura global del gas es baja (Bourke et al., 2018; Niemira, 2012; Scholtz et al., 2015), es ideal para la agricultura (Mir et al., 2020), áreas médicas, sanitarias (Patil et al., 2016), para otras industrias como la textil, la electrónica y alimentaria (Chen et al., 2019), recalcando que el PFA es el más usado en el procesamiento de los alimentos (Chizoba et al., 2017; Kaluwahandi et al., 2020; Pan et al., 2019a; Pan et al., 2020). Un ejemplo de plasma no térmico es una lámpara fluorescente (Schlüter et al., 2013).

\section{Aplicación del plasma frío como tecnología de conservación alimentaria}

El PF se propone como una tecnología de conservación no térmica con alto potencial para prolongar la vida de anaquel de los alimentos (Liao et al., 2020; Pan et al., 2019a; Sonawane et al., 2020; Ziuzina et al., 2014), basándose en la descontaminación microbiana (Bermúdez-Aguirre et al., 2013; Bourke et al., 2018; Mandal et al., 2018; Misra et al., 2016; Niemira y Sites, 2008; Pasquali et al., 2016; Patil et al., 2016; Sonawane et al., 2020; Stoica et al., 2014), y la inactivación enzimática (Almeida et al., 2017; Bourke et al., 2017; Surowzky et al., 2013; Ozen y Singh, 2020; Pan et al., 2019b).

De igual manera, según la investigación de Gavahian et al. (2020), el PF ataca los enlaces químicos de muchos plaguicidas comunes (como el paratión, ciprodinil y fludioxonil) y alérgenos alimentarios (tropomiosina, inhibidor de la tripsina, entre otros). 
Los MO patógenos son el principal problema de seguridad alimentaria (Bourke et al., 2017) por agentes como las bacterias, hongos, esporas y virus (Bourke et al., 2018; Lacombe et al., 2015; Misra et al., 2019; Mostafidi et al., 2020; Pankaj y Keener, 2017; Pasquali et al., 2016; Stoica et al., 2014; Thirumdas et al., 2015), los cuales son culpables de las ETAs, pudiendo causar infección, alergia, intoxicación (Scholtz et al., 2015) y hasta la muerte del consumidor.

Según lo recopilado, el PF demostró eficacia en la descontaminación de MO incluyendo sus toxinas en gran variedad de alimentos (Figura 2) como frutas y verduras (Ji et al., 2020; Kaluwahandi et al., 2020; Niemira, 2012; Pan et al., 2019a), productos cárnicos, lácteos y derivados (Bourke et al., 2017; Stoica et al., 2014), frutos secos, cereales, granos (Bourke et al., 2017; Gavahian et al., 2018; Misra et al., 2018) y productos procesados (Almeida et al., 2017; Feizollahi et al., 2020; Ozen y Singh, 2020).

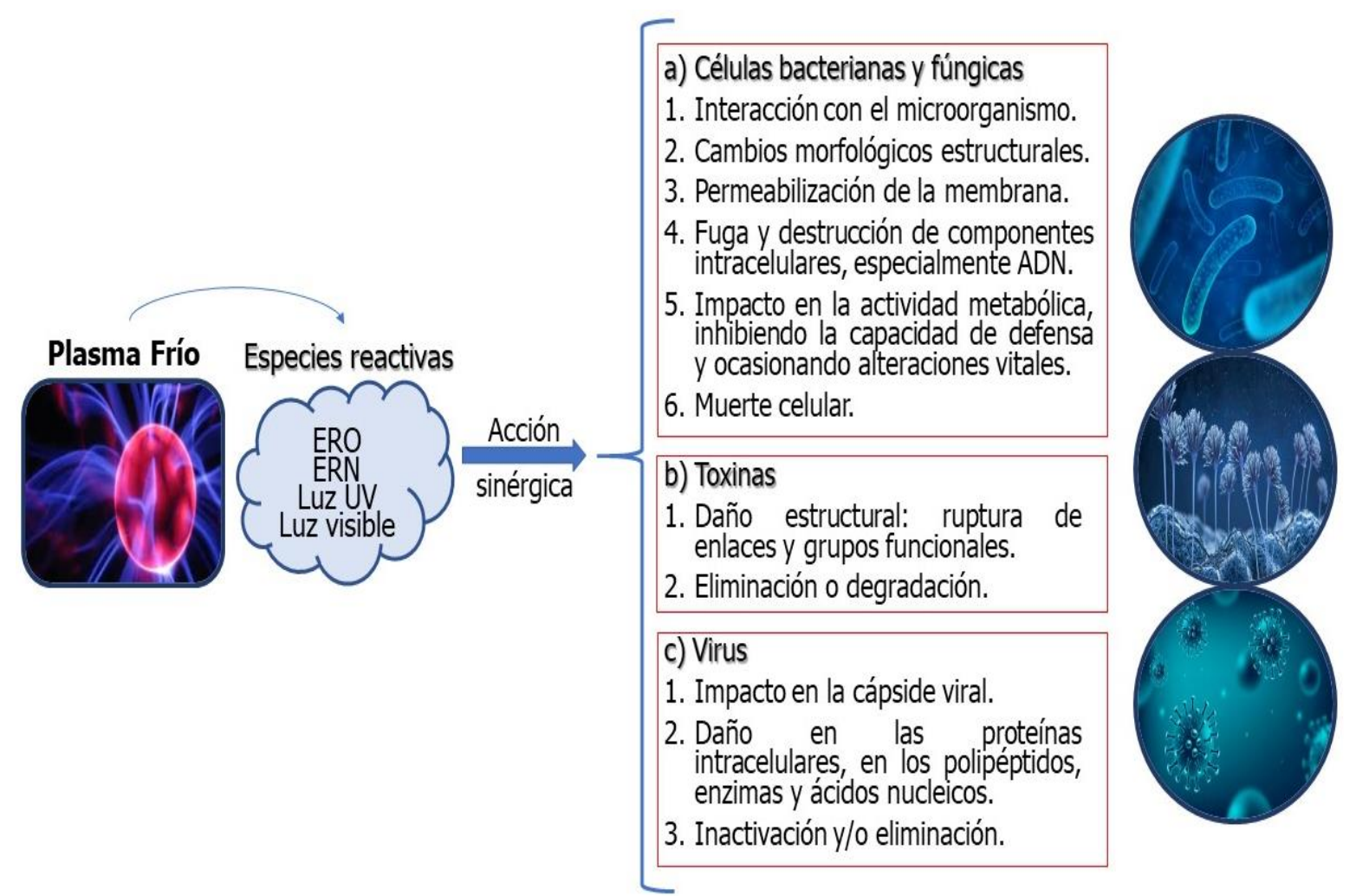

Figura 2. Actividad antimicrobiana del PF: a) efectos generales contra bacterias y hongos, b) efectos específicos en toxinas bacterianas y fúngicas, c) algunos efectos ocasionados en virus.

Las reacciones enzimáticas también son una preocupación para la industria alimenticia (Scholtz et al., 2015; Ozen y Singh, 2020) al ocasionar cambios negativos en la composición (Pankaj et al., 2013; Surowzky et al., 2013), repercutiendo en su calidad, por la cual deben de ser inactivadas o inhibidas. 


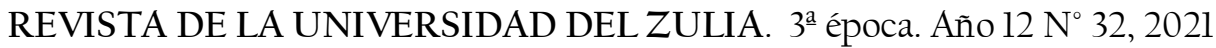

Vicente Tirado-Kulieva et al. // Análisis crítico del potencial del plasma frío como tecnología ...284-316

DOI: http://dx.doi.org/10.46925//rdluz.32.18

\subsection{Potencial antimicrobiano}

El PF al ser una tecnología no térmica, la temperatura no es un factor que tenga mucha influencia en la esterilización (Patil et al., 2016). Su eficacia se ve afectada por la matriz alimentaria (Liao et al., 2017), tipo de MO y población inicial (Pasquali et al., 2016; Phan et al., 2017), las condiciones de operación: temperatura (Pan et al., 2019b), pH, humedad relativa, potencial de oxidación-reducción (redox), conductividad (Pan et al., 2019a), potencia y voltaje, el tiempo de procesamiento, tipo de exposición (directa o indirecta) tipo de gas, tipo de fuente del plasma (Patil et al., 2016), especialmente, la cantidad y cualidad de ER generadas (Alves et al., 2020; Bourke et al., 2017; Feizollahi et al., 2020; Gavahian et al., 2018; Misra et al., 2011; Misra et al., 2019; Niemira, 2012; Pan et al., 2019a; Pankaj et al., 2014; Stoica et al., 2014), radiación UV (Lacombe et al., 2015), visible e infrarroja (Coutinho et al., 2018), las cuales atacan a múltiples objetivos de la célula microbiana (Hati et al., 2018; Patil et al., 2016).

Las ER más estudiadas con respecto a su asociación en el efecto microbiano del PF, son ERO como el $\mathrm{O}_{2}, \mathrm{O}_{2}^{-}, \mathrm{O}_{3}, \mathrm{H}_{2} \mathrm{O}_{2}$ (Chizoba et al., 2017; Mandal et al., 2018), el peroxilo (ROO), hidroperoxilo $\left(\mathrm{HO}_{2}\right)$, etc. y ERN como $\mathrm{NO}$, dióxido de nitrógeno $\left(\mathrm{NO}_{2}\right)$ (Coutinho et al., 2018; Stoica et al., 2014), ácido peroxinitroso (ONOO'), entre otras (Misra et al., 2017).

Un estudio de Kaluwahandi et al. (2020) informó que Ar mezclado con aire y agua activada por PF tiene una fuerte actividad viral, basándose en el efecto que ocasiona a las cadenas de polipéptidos, dañando la cápside viral. Como complemento, Stoica et al. (2014) indicaron que la efectividad del PF contra los virus se da por la permeabilización de la membrana celular, la inactivación de enzimas y el daño que causa a sus proteínas intracelulares y ácidos nucleicos.

La mayoría de investigaciones concernientes a la descontaminación microbiana aplicando PF es sobre el efecto contra las bacterias y hongos, principales agentes microbianos en gran variedad de alimentos, incluyendo sus respectivos mecanismos de inactivación (Tabla $1)$.

\subsubsection{Efecto antibacteriano}

Según diversos estudios, el PF ha sido usado para desinfectar y/o esterilizar muchos alimentos, principalmente de bacterias patógenas. Entre las que fueron afectados eficazmente se encuentran la Escherichia coli (Baier et al., 2014; Bermúdez-Aguirre et al., 2013; 


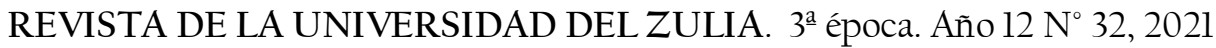

Vicente Tirado-Kulieva et al. // Análisis crítico del potencial del plasma frío como tecnología ...284-316

DOI: http://dx.doi.org/10.46925//rdluz.32.18

Mohamed et al., 2016; Ziuzina et al., 2014), Salmonella enterica Typhimurium, Listeria monocytogenes (Niemira, 2012; Pankaj et al., 2014; Pasquali et al., 2016; Ziuzina et al., 2014), Bacillus cereus, Pseudomonas aeruginosa y Staphylococcus aureus (Alkawareek et al., 2014).

El mecanismo de acción antibacterial producto de todas las ER se da porque estas al penetrar su célula (Bourke et al., 2017; Misra et al., 2016; Pasquali et al., 2016), inician una interacción química (Kaluwahandi et al., 2020; Niemira, 2012; Phan et al., 2017), dañando sus membranas, permeabilizándolas, dando lugar a la fuga del ADN (Kaluwahandi et al., 2020; Lacombe et al., 2015; Niemira, 2012; Misra et al., 2016; Phan et al., 2017), componentes como el potasio, ácidos nucleicos, proteínas metabólicas (Stoica et al., 2014), inactivación de enzimas (Pankaj y Keener, 2017), impacto en sus fosfolípidos y peptidoglicano por la formación de peróxidos y aniones superóxidos (Misra et al., 2016) y que al evitar que las bacterias activen sus defensas (Phan et al., 2017) o realicen alguna otra actividad metabólica (Bourke et al., 2018) por la pérdida de la funcionalidad (Feizollahi et al., 2020), se provocan alteraciones vitales (Bao et al., 2020a), hasta inducir la apoptosis o muerte celular (Munekata et al., 2020).

La perturbación de la membrana celular se da por las fuerzas electroestáticas generadas lo que ocasiona la electroporación y, por ende, la formación de poros, repercutiendo en la fuga del contenido y posterior muerte de la célula (Feizollahi et al., 2020; Lunov et al., 2015), lo cual fue comprobado mediante microscopía electrónica de barrido por Bermúdez-Aguirre et al. (2013), quienes sostienen que las ER al ingresar a la célula, reaccionan con sus componentes principales como las mitocondrias y el núcleo e incluso, según Hati et al. (2018), el ADN, involucrando a los rayos UV en la dimerización de la timina y citosina. De forma específica, las ERO y ERN al ser los principales agentes bactericidas (Misra et al., 2016), siendo las ERO las que cumplen el rol protagónico (Cheng et al., 2020; Pankaj y Keener, 2017), Alkawareek et al. (2014); Bermúdez-Aguirre et al. (2013); Feizollahi et al. (2020); Liao et al. (2017); Pasquali et al. (2016); Surowzky et al. (2013) manifiestan que inducen a la peroxidación lipídica de las membranas microbianas, ocasionando daño oxidativo, ruptura de la membrana y fuga del material intracelular. De acuerdo con Stoica et al. (2014), la toxicidad de los radicales $\mathrm{OH}$ influye mayoritariamente en dicho efecto. 
REVISTA DE LA UNIVERSIDAD DEL ZULIA. $3^{a}$ época. Año $12 \mathrm{~N}^{\circ} 32,2021$ Vicente Tirado-Kulieva et al. // Análisis crítico del potencial del plasma frío como tecnología ...284-316 DOI: http://dx.doi.org/10.46925//rdluz.32.18

Tabla 1. Hallazgos sobre la aplicación de PF en la descontaminación microbiana de los productos alimenticios.

\begin{tabular}{|c|c|c|c|c|c|c|}
\hline Matriz alimentaria & Microorganismo & $\begin{array}{c}\text { Gas de } \\
\text { alimentació } \\
\mathbf{n}\end{array}$ & $\begin{array}{l}\text { Fuente de } \\
\text { plasma }\end{array}$ & $\begin{array}{l}\text { Mejores parámetros } \\
\text { del proceso }\end{array}$ & Reducción microbiana & Referencias \\
\hline $\begin{array}{l}\text { Ensalada de maíz, } \\
\text { pepino, manzana y } \\
\text { tomate }\end{array}$ & $\begin{array}{c}\text { Escherichia coli DSM } \\
1116\end{array}$ & $\mathrm{Ar}+0.1 \% \mathrm{O}_{2}$ & CPAT & $\begin{array}{l}\text { P: } 8 \mathrm{~W}, \mathrm{~V}: 6 \mathrm{kV}, \mathrm{f}: 1.1 \\
\mathrm{MHz}, \Phi: 5 \mathrm{~L} / \mathrm{min}, \mathrm{t}: \\
60 \mathrm{~s}\end{array}$ & $\begin{array}{l}1 \pm 1.2,4.7 \pm 0.4,4.7 \pm 0, \text { y } 3.3 \\
\pm 0.9 \text { unidades logarítmicas }\end{array}$ & $\begin{array}{l}\text { Baier et al. } \\
\text { (2014) }\end{array}$ \\
\hline $\begin{array}{l}\text { Lechuga, zanahoria } \\
\text { y tomate }\end{array}$ & E. coli & $\mathrm{Ar}$ & $\mathrm{CP}$ & $\begin{array}{l}\mathrm{V}: 12.83 \mathrm{kV}, \mathrm{f}: 60 \mathrm{~Hz} \\
\Phi: 455.33 \mathrm{~cm}^{3} / \mathrm{min} \mathrm{t}: \\
10 \mathrm{~min}\end{array}$ & 1.6 ciclos logarítmicos & $\begin{array}{l}\text { Bermúdez- } \\
\text { Aguirre et } \\
\text { al. (2013) }\end{array}$ \\
\hline Arándanos & $\begin{array}{c}\text { Bacterias aeróbicas y } \\
\text { moho nativo }\end{array}$ & Aire & DBD & $\begin{array}{l}\mathrm{V}: 12 \mathrm{kV}, \mathrm{f}: 5 \mathrm{~Hz}, \mathrm{t}: 60 \\
\mathrm{~s}\end{array}$ & $\begin{array}{l}0.34-1.24 \text { y } 0.57-0.87 \text { log } \\
\text { UFC/g para bacterias y } \\
\text { moho, respectivamente }\end{array}$ & $\begin{array}{l}\text { Ji et al. } \\
(2020)\end{array}$ \\
\hline $\begin{array}{l}\text { Polvo de pimienta } \\
\text { roja }\end{array}$ & $\begin{array}{l}\text { Aspergillus flavus y } \\
\text { Bacillus cereus }\end{array}$ & $\begin{array}{l}\mathrm{N}_{2} \mathrm{y} \mathrm{He}-\mathrm{O}_{2} \\
(9.8: 0.2)\end{array}$ & $\mathrm{MO}$ & $\begin{array}{l}\text { P: } 900 \mathrm{~W} \text {, p: } 667 \mathrm{~Pa} \text {, } \\
\Phi: 1 \mathrm{~L} / \mathrm{min}, \mathrm{t}: 20 \mathrm{~min} \\
\text { (A.flavus) y } 30 \mathrm{~min}(B . \\
\text { cereus) }\end{array}$ & $\begin{array}{l}2.5 \pm 0.3 \log \text { esporas } / g \text { de } \\
\text { plasma en A. flavus, usando } \\
\mathrm{N}_{2} \text { y } 3.4 \pm 0.7 \log \text { esporas } / g \\
\text { en B. cereus, } \mathrm{He}-\mathrm{O}_{2}\end{array}$ & $\begin{array}{l}\text { Kim et al. } \\
(2014)\end{array}$ \\
\hline Polvo de cebolla & $\begin{array}{c}\text { Aspergillus brasiliensis, } \\
\text { B. cereus y E. coli } \\
\text { Ol57:H7 }\end{array}$ & $\mathrm{He}$ & $\mathrm{MO}$ & $\begin{array}{l}\text { P: } 400 \mathrm{~W}, \mathrm{p}: 0.7 \mathrm{kPa}, \\
\Phi: 1 \mathrm{~L} / \mathrm{min}, \mathrm{t}: 40 \mathrm{~min}\end{array}$ & $\begin{array}{l}\text { 2.1, } 1.6 \text { y } 1.9 \text { log esporas } / \mathrm{cm}^{2} \\
\text { en A. brasiliensis, B. cereus y E. } \\
\text { coli, respectivamente }\end{array}$ & $\begin{array}{l}\text { Kim et al. } \\
(2017)\end{array}$ \\
\hline Arándanos & $\begin{array}{c}\text { Microflora nativa } \\
\text { (bacterias aerobias } \\
\text { totales y } \\
\text { levaduras/mohos) }\end{array}$ & Aire & PFA & $\begin{array}{l}\text { P: } 549 \mathrm{~W}, \mathrm{f}: 47 \mathrm{kHz} \\
\Phi: 4 \mathrm{pies}^{3} / \mathrm{min}, \mathrm{p}: 60 \\
\text { psi, t: } 15-120 \mathrm{~s}\end{array}$ & $\begin{array}{l}0.8-1.6 \text { log UFC/g en } \\
\text { bacterias y } 1.5-2 \text { log } \\
\text { UFC/g } \\
\text { levaduras/mohos }\end{array}$ & $\begin{array}{l}\text { Lacombe et } \\
\text { al. (2015) }\end{array}$ \\
\hline Fresas & $\begin{array}{c}\text { Bacterias mesófilas } \\
\text { aerobias, levaduras y } \\
\text { moho nativo }\end{array}$ & Aire & DBD & $\begin{array}{l}\mathrm{V}: \mathrm{kV}, \mathrm{f}: 50 \mathrm{~Hz}, \mathrm{HR}: \\
42 \%, \mathrm{t}: 5 \mathrm{~min}\end{array}$ & $\begin{array}{l}2 \text { log para las bacterias, } \\
\text { levaduras y moho }\end{array}$ & $\begin{array}{l}\text { Misra et al. } \\
(2014) \text {. }\end{array}$ \\
\hline $\begin{array}{l}\text { Manzana Golden } \\
\text { Delicious }\end{array}$ & $\begin{array}{l}\text { E-coli Ol57:H7 y } \\
\text { Salmonella stanley }\end{array}$ & Aire & $\mathrm{AD}$ & $\begin{array}{l}\mathrm{V}: 30 \mathrm{kV}, \mathrm{f}: \mathrm{Hz}, \Phi: 40 \\
\mathrm{~L} / \mathrm{min}, \mathrm{t}: 3 \mathrm{~min}\end{array}$ & $\begin{array}{l}3.4-3.6 \log \mathrm{UFC} / \mathrm{ml} \text { en } E . \\
\text { coli y } 2.9-3.7 \mathrm{UFC} / \mathrm{ml} \text { en } S \text {. } \\
\text { stanley }\end{array}$ & $\begin{array}{l}\text { Niemira } \\
(2008)\end{array}$ \\
\hline
\end{tabular}


REVISTA DE LA UNIVERSIDAD DEL ZULIA. $3^{a}$ época. Año $12 \mathrm{~N}^{\circ} 32,2021$ Vicente Tirado-Kulieva et al. // Análisis crítico del potencial del plasma frío como tecnología ...284-316 DOI: http://dx.doi.org/10.46925//rdluz.32.18

\begin{tabular}{|c|c|c|c|c|c|c|}
\hline Achicoria roja & $\begin{array}{c}\text { E. coli Ol57:H7 y } \\
\text { Listeria monocytogenes }\end{array}$ & Aire & DBD & $\begin{array}{l}\mathrm{V}: 15 \mathrm{kV}, \mathrm{f}: 12.5 \mathrm{kHz}, \\
\Phi: 7 \times 10^{-3} \mathrm{~m}^{3} / \mathrm{s}, \mathrm{HR}: \\
60 \%, \mathrm{t}: 15 \mathrm{~min} \text { (E.coli) } \\
\mathrm{y} \quad 30 \quad \min \quad(\mathrm{L} . \\
\text { monocytogenes) }\end{array}$ & $\begin{array}{l}1.35 \log \mathrm{NMP} / \mathrm{cm}^{2} \text { en E. coli } \\
\text { y } 2.2 \mathrm{log} \mathrm{UFC} / \mathrm{cm}^{2} \text { en L. } \\
\text { monocytogenes }\end{array}$ & $\begin{array}{l}\text { Pasquali et } \\
\text { al. (2016) }\end{array}$ \\
\hline $\begin{array}{l}\text { Semilla de tomate, } \\
\text { de garbanzo, avena, } \\
\text { trigo, frijol de soja, } \\
\text { cebada, frijol, maíz, } \\
\text { centeno y lentejas }\end{array}$ & $\begin{array}{l}\text { Aspergillus spp. y } \\
\text { Penicillum spp. }\end{array}$ & $\begin{array}{l}\text { Hexafluoruro } \\
\text { de azufre } \\
\left(\mathrm{SF}_{6}\right)\end{array}$ & $\mathrm{MO}$ & $\begin{array}{l}\text { P: } 300 \text { W, p: } 500 \\
\text { mTorr, t: } 15 \text { min }\end{array}$ & $\begin{array}{l}3 \text { log para ambos hongos en } \\
\text { todas las semillas }\end{array}$ & $\begin{array}{l}\text { Selcuk et al. } \\
\quad(2008)\end{array}$ \\
\hline Jugo de manzana & Citrobacter freundii & $\mathrm{Ar}+0.1 \% \mathrm{O}_{2}$ & $\mathrm{CP}$ & $\begin{array}{l}\mathrm{V}: 65 \mathrm{~V}, \mathrm{f}: 1.1 \mathrm{MHz}, \Phi: \\
5 \mathrm{~L} / \mathrm{min}, \mathrm{T}: 480 \mathrm{~s}\end{array}$ & 5 ciclos logarítmicos & $\begin{array}{l}\text { Surowzky } \\
\text { et al. }(2014)\end{array}$ \\
\hline $\begin{array}{l}\text { Paocai (rábano } \\
\text { fermentado) }\end{array}$ & Levaduras nativas & Aire & DBD & $\begin{array}{l}\text { V: } 60 \mathrm{kV}, \mathrm{f}: 50 \mathrm{~Hz} \\
\text { HR: } 45 \%, \mathrm{t}: 60 \mathrm{~s}\end{array}$ & $\begin{array}{l}\text { Eliminación total de las } \\
\text { levaduras, reteniendo y } \\
\text { propiciando la } \\
\text { propagación de las } \\
\text { bacterias ácido lácticas, de } \\
\text { importancia fermentativa }\end{array}$ & $\begin{array}{l}\text { Zhao et al. } \\
\text { (2020) }\end{array}$ \\
\hline $\begin{array}{l}\text { Tomates, cerezas y } \\
\text { fresas }\end{array}$ & $\begin{array}{l}\text { E. coli, Salmonella } \\
\text { entérica serovar } \\
\text { Typhimurium y L. } \\
\text { monocytogenes }\end{array}$ & Aire & DBD & $\mathrm{V}: 70 \mathrm{kV}_{\mathrm{RMS}}, \mathrm{t}: 300 \mathrm{~s}$ & $\begin{array}{lrrr}4.2, \quad 3.8 \quad \text { y } & 3.5 & \text { log } \\
\text { UFC/muestra } & \text { en } & \text { L. } \\
\text { monocytogenes, } & \text { S. Stanley } \\
\text { y E. coli, respectivamente }\end{array}$ & $\begin{array}{l}\text { Ziuzina et } \\
\text { al. (2014) }\end{array}$ \\
\hline
\end{tabular}

Nota: $\mathrm{P}$ = potencia, $\mathrm{V}$ = voltaje, $\mathrm{f}=$ frecuencia, $\mathrm{HR}$ : humedad relativa, $\mathrm{p}$ = presión, $\Phi$ = flujo volumétrico, $\mathrm{t}=$ tiempo, $\mathrm{NMP}$ = número más probable,

UFC = unidad formadora de colonias, RMS = root men square, también llamado voltaje eficaz 


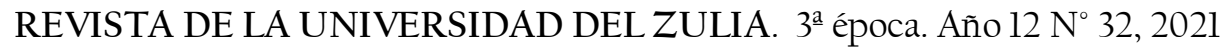

Vicente Tirado-Kulieva et al. // Análisis crítico del potencial del plasma frío como tecnología ...284-316

DOI: http://dx.doi.org/10.46925//rdluz.32.18

De acuerdo a múltiples investigaciones, las bacterias Gram negativas tienen mayor susceptibilidad a los efectos del PF que las Gram positivas, debido a que estas últimas tienen mayor cantidad de peptidoglicano y mayor estabilidad en su pared celular, frente al menor contenido de las negativas (Bourke et al., 2017; Liao et al., 2017). Como era de suponerse, Bourke et al. (2017) agregan que las bacterias anaerobias son muy sensibles a las ERO, quienes les causan daños significativos a su membrana citoplasmática y ADN.

\subsubsection{Efecto antifúngico}

Los hongos, especialmente los mohos son responsables de cambios indeseables y hasta del deterioro en muchos alimentos (Kaluwahandi et al., 2020), lo cual tiene un fuerte impacto negativo en la seguirdad alimentaria (Adebo et al., 2020; Misra et al., 2018). Con base en Misra et al. (2018), los hongos se desarrollan en todo tipo de alimentos, causándoles decoloración, sabor desagradable, propágulos y putrefacción.

Las micotoxinas producidas por hongos de los géneros Aspergillus, Alternaria, Fusarium, Penicillium (Adebo et al., 2020; Misra et al., 2018), Stachybotrys y Claviceps (Adebo et al., 2020), suponen el mayor riesgo de este tipo de MO, las cuales pueden contaminar al producto en distintas etapas de la cadena alimentaria. De acuerdo con Annapure (2018), las aflatoxinas son las más tóxicas, cancerígenas y teratogénicas de todas las micotoxinas y que son producidas por Aspergillus flavus y Aspergillus parasiticus.

Para contrarrestar la contaminación fúngica en los alimentos, el PF emerge como alternativa de esterilización no térmica que ya ha sido probada, obteniendo resultados favorables (Kaluwahandi et al., 2020) contra Aspergillus spp, Penicillium spp. (Selcuk et al., 2018), algunas levaduras nativas indeseables (Zhao et al., 2020), y especies específicas como A. brasiliensis (Kim et al., 2017), A. flavus (Kim et al., 2014), entre otras. Adicionalmente, el PF también mostró potencial contra las micotoxinas (Adebo et al., 2020; Pankaj y Keener, 2017) y esporas (Kim et al., 2014; Misra et al., 2018; Pankaj et al., 2014), siendo las más resistentes y de difícil eliminación.

El mecanismo del efecto frente a los hongos es que, al tener contacto con las ER del PF que actúan de manera sinérgica (Kaluwahandi et al., 2020), estas inactivan las funciones de la membrana celular, causan cambios morfológicos en su estructura, 
aumentando la permeabilidad, ocasionando oxidación y fuga del material intracelular, especialmente el ADN, conllevando a la apoptosis de las células fúngicas (Misra et al., 2018; Misra et al., 2019; Pan et al., 2020). Además, según Misra et al. (2018) causan otros daños como la deformación en la punta del micelo y destrucción de diversos componentes celulares como las proteínas (Misra et al., 2018).

La descomposición de las micotoxinas se origina por la interrupción de las funciones celulares de los hongos, lo que ocasiona la degradación estructural (Misra et al., 2018), la ruptura de enlaces y de grupos funcionales (Adebo et al., 2020). Finalmente, las micotoxinas pueden ser eliminadas o degradadas a otros productos menos tóxicos (Misra et al., 2018).

Es preciso destacar que las células fúngicas tienen mayor resistencia que las bacterianas ya que los hongos poseen una pared celular más rígida compuesta de quitina (Liao et al., 2017) frente a la de las bacterias que, aunque está constituida por peptidoglicano, es menos gruesa,

\subsection{Inactivación de enzimas}

Las enzimás endógenas son otro factor de descomposición de los alimentos, pudiendo afectar su calidad por los cambios que genera en sus características sensoriales como olor, color (decoloración) y sabor (enranciamiento), fisicoquímicas como la textura y viscosidad, y nutricionales como ocasionar un desequilibrio en el metabolismo fenólico y catalizar reacciones de peroxidación (Han et al., 2019; Mir et al., 2020; Pankaj et al., 2013; Pasquali et al., 2016; Surowzky et al., 2013). Las más comunes en frutas y hortalizas son la lipasa (LPS) y lipoxigenasa (LOX), causantes del enranciamiento; la polifenol oxidasa (PFO) y peroxidasa (POX) que ocasionan pardeamiento y decoloración (Han et al., 2019; Misra et al., 2016; Pankaj et al., 2013), siendo estas dos últimas, las principales (Surowzky et al., 2013; Thirumdas y Sarangapani, 2015) y, además, la pectin metil esterasa (PME), agente causante del ablandamiento (Pan et al., 2020).

Considerando el impacto negativo en la seguridad alimentaria en general, usualmente se emplean tecnologías térmicas para inactivar las enzimas, como la esterilización, pasteurización y escaldado (Ozen y Singh, 2020; Pankaj et al., 2013), que 


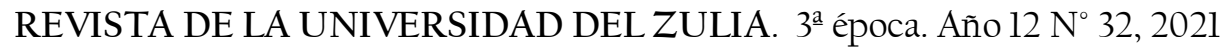
Vicente Tirado-Kulieva et al. // Análisis crítico del potencial del plasma frío como tecnología ...284-316

DOI: http://dx.doi.org/10.46925//rdluz.32.18

al afectar también las características del alimento, el PF se origina para resolver esa problemática, demostrando un enorme potencial como técnica no destructiva de conservación alimentaria (Han et al., 2019; Mir et al., 2020; Misra et al., 2016; Munekata et al., 2020; Pan et al., 2019a; Surowzky et al., 2013; Thirumdas et al., 2017; Thirumdas y Sarangapani, 2015).

El mecanismo de inactivación de enzimas, al ser una proteína, se basa por el efecto que tienen las ER en la estructura primaria, secundaria y terciaria (Figura 3) (Han et al., 2019; Munekata et al., 2020), ocasionando rupturas o modificaciones en sus enlaces, especialmente en los principales (Misra et al., 2016). Inducen cambios químicos en la cadena de aminoácidos como triptófano, cisteína y tirosina (Khani et al., 2017), degradan grupos funcionales de importancia como el carboxilo (- $\mathrm{COOH})$ y amino $\left(-\mathrm{NH}_{2}\right)$ (Misra et al., 2016; Munekata et al., 2020).
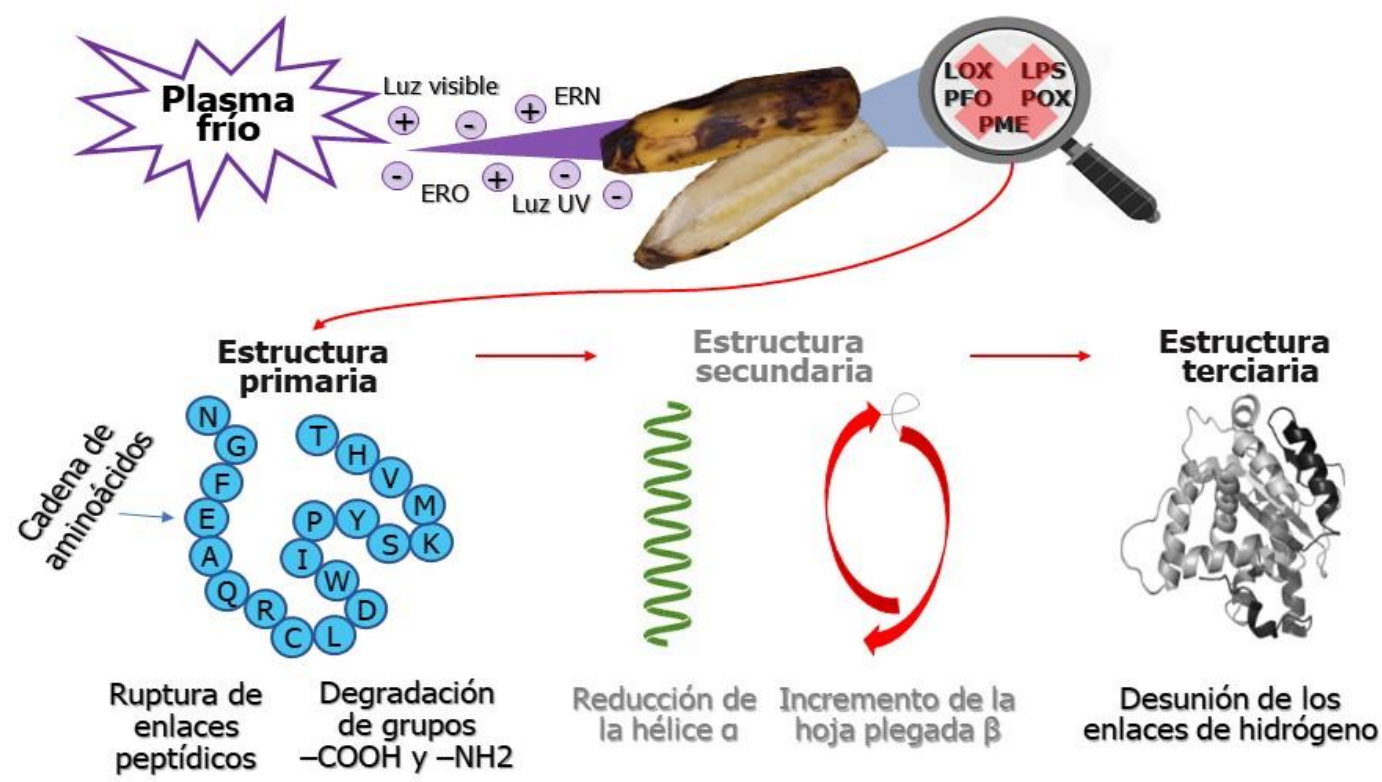

Figura 3. Daño causado en la estructura primaria, secundaria y terciaria de las enzimas endógenas de los alimentos por efecto de la interacción química de las especies reactivas del plasma frío.

Específicamente se ha demostrado que el PF provoca la reducción o pérdida de la estructura secundaria hélice alfa ( $\alpha$ ) y el incremento de la hoja beta ( $\beta$ ) (Khani et al., 2017; Han et al., 2019; Munekata et al., 2020; Surowzky et al., 2013). En la estructura terciaria, Alkawareek et al. (2014) indican que el PF la afecta de distintas maneras, 


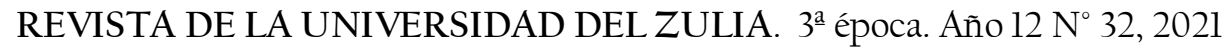

Vicente Tirado-Kulieva et al. // Análisis crítico del potencial del plasma frío como tecnología ...284-316

DOI: http://dx.doi.org/10.46925//rdluz.32.18

incluyendo la oxidación de las cadenas laterales de aminoácidos o la interrupción de la unión de los enlaces de hidrógeno.

Además de reducir o inactivar la actividad de las enzimas indeseables, tal y como demostraron Han et al. (2019), el PF puede aumentar la actividad de las enzimas de interés alimentario y para la salud como la $\alpha$-amilasa y antioxidantes como la CAT y superóxido dismutasa (SOD).

En la investigación de Khani et al. (2017), emplearon una mezcla de aire y He, y DBD como fuente para generar PF y aplicarlo en la inactivación de la POX del tomate, obteniendo mejores resultados con P: $20 \mathrm{~W}$, V: $10 \mathrm{kV}$, f: $20 \mathrm{kHz}$, $\Phi: 3 \mathrm{~L} / \mathrm{min}$ y t: 4 min., logrando una reducción significativa de la actividad enzimática de $100 \%$ a 3.71\%, demostrando eficacia para evitar la degradación de la calidad de los alimentos. Pankaj et al. (2013) se enfocaron en el mismo alimento y enzima con V: 30, 40 y $50 \mathrm{kV}$ y t: 1-5 min, concluyendo que la actividad de la POX disminuía a a medida que pasaba el tiempo de tratamiento y aumentaba el voltaje, es decir, existía una relación inversamente proporcional, siendo un factor de suma importancia a tener en cuenta para posteriores experimentaciones.

Particularmente, en los resultados de Ji et al. (2020) aplicando PF en arándanos en condiciones de almacenamiento, a partir de aire y DBD con V: $2 \mathrm{kV}$, f: $5 \mathrm{~Hz}$, HR: 65\%, t: $60 \mathrm{~s}$ y t almacenamiento: 0-40 días, se notó que la actividad de las enzimas POX y SOD fue menor en los primeros 20 días con respecto a la muestra control, pero posteriormente, aumentó. En el caso de la CAT, su actividad se mantuvo por encima de la muestra control, teniendo enormes diferencias a partir del día 30, cuando la actividad en la muestra control, eran mínimas. Estos datos obtenidos demuestran que debe de haber una evaluación más exhaustiva sobre el efecto del PF en las enzimas endógenas alimentarias al igual que su mecanismo, para poder tener un mayor entendimiento sobre las interacciones químicas y lograr formular un modelo matemático que pueda predecir los resultados.

Asimismo, Surowzky et al. (2013) determinaron en su estudio que el PF generado por CP con una mezcla de Ar y 0.1\% de $\mathrm{O}_{2}$, V: $65 \mathrm{~V}$, f: $1.1 \mathrm{MHz}$, $\Phi: 5 \mathrm{~L} / \mathrm{min}$ y t: 0-360 s, es capaz de reducir la actividad enzimática de PFO y POX en un sistema alimentario modelo. La reducción fue de $90 \%$ después de 180 s, y de $85 \%$, a los 240 s, 
para el PFO y POX, respectivamente. Se concluyó que el efecto se basaba en la modificación de la estructura secundaria de la enzima, ocasionando la disminución de la hélice $\alpha$ y el aumento de la región de la hoja $\beta$.

\section{Plasma Frío en el procesamiento de los alimentos}

El PF además de emplearse como tecnología de conservación de los alimentos, tiene potencial en otras operaciones en el procesamiento alimentario (Figura 4) (Bao et al., 2020a; Bourke et al., 2018; Feizollahi et al., 2020; Han et al., 2019; Hati et al., 2018; Pan et al., 2019b; Surowzky et al., 2013), como en la descontaminación de superficies inertes (Hati et al., 2018), biomateriales (Gavahian et al., 2018; Pankaj et al., 2013) y equipo de procesamiento (Mostafidi et al., 2020; Surowzky et al., 2014), degradación de plaguicidas (Bourke et al., 2017; Gavahian et al., 2020; Mir et al., 2020; Pan et al., 2019b; Phan et al., 2017), alérgenos (Gavahian et al., 2020; Mohamed et al., 2016; Sarangapani et al., 2018), reducción y/o eliminación de componentes antinutricionales y otros compuestos tóxicos (Pankaj y Keener, 2017), modificación de la humectabilidad de la superficie (Grzegorzewski et al., 2010), modificación fisicoquímica del almidón (Chizoba et al., 2017; Gavahian et al., 2018; Mostafidi et al., 2020; Sarangapani et al., 2018; Sonawane et al., 2020; Thirumdas et al., 2017), modificación del material de envasado (Oh et al., 2016; Pankaj et al., 2014; Sonawane et al., 2020), hidrogenación de aceites vegetales para generar aceites libres de trans (Mohamed et al., 2016), germinación de semillas como alimentos funcionales (Charoux et al., 2020; Hati et al., 2018; Thirumdas et al., 2017) e incluso en el tratamiento de aguas residuales (Chizoba et al., 2017; Jiang et al., 2016; Hati et al., 2018; Mohamed et al., 2016).

\subsection{Impacto en la calidad alimentaria}

Con el pasar del tiempo, es mayor el interés por la búsqueda de tecnologías innovadoras de procesamiento alimentario que además de que ayuden a obtener alimentos seguros, estos mantengan su calidad (Mir et al., 2020; Misra et al., 2011). El PF, al emplearse en bajas temperaturas, se evitan efectos térmicos indeseables, manteniendo íntegramente las características de los productos (Alves et al., 2020; Almeida et al., 2017; Charoux et al., 2020; Cheng et al., 2020; Feizollahi et al., 2020; Grzegorzewski et al., 2010; Ji et al., 2020; Liao et al., 2020; Misra et al., 2015; Pan et al., 


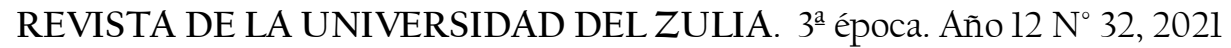

Vicente Tirado-Kulieva et al. // Análisis crítico del potencial del plasma frío como tecnología ...284-316

DOI: http://dx.doi.org/10.46925//rdluz.32.18

2019b; Sarangapani et al., 2018; Scholtz et al., 2015; Thirumdas y Sarangapani, 2015), minimizando los daños especialmente para los compuestos termosensibles (Alves et al., 2020; Coutinho et al., 2018; Mir et al., 2020; Misra et al., 2018; Niemira, 2012; PérezAndrés et al., 2019; Phan et al., 2017; Scholtz et al., 2015; Sonawane et al., 2020). Adicionalmente, ofrece la ventaja de influir positivamente en las características alimentarias (Tabla 2).

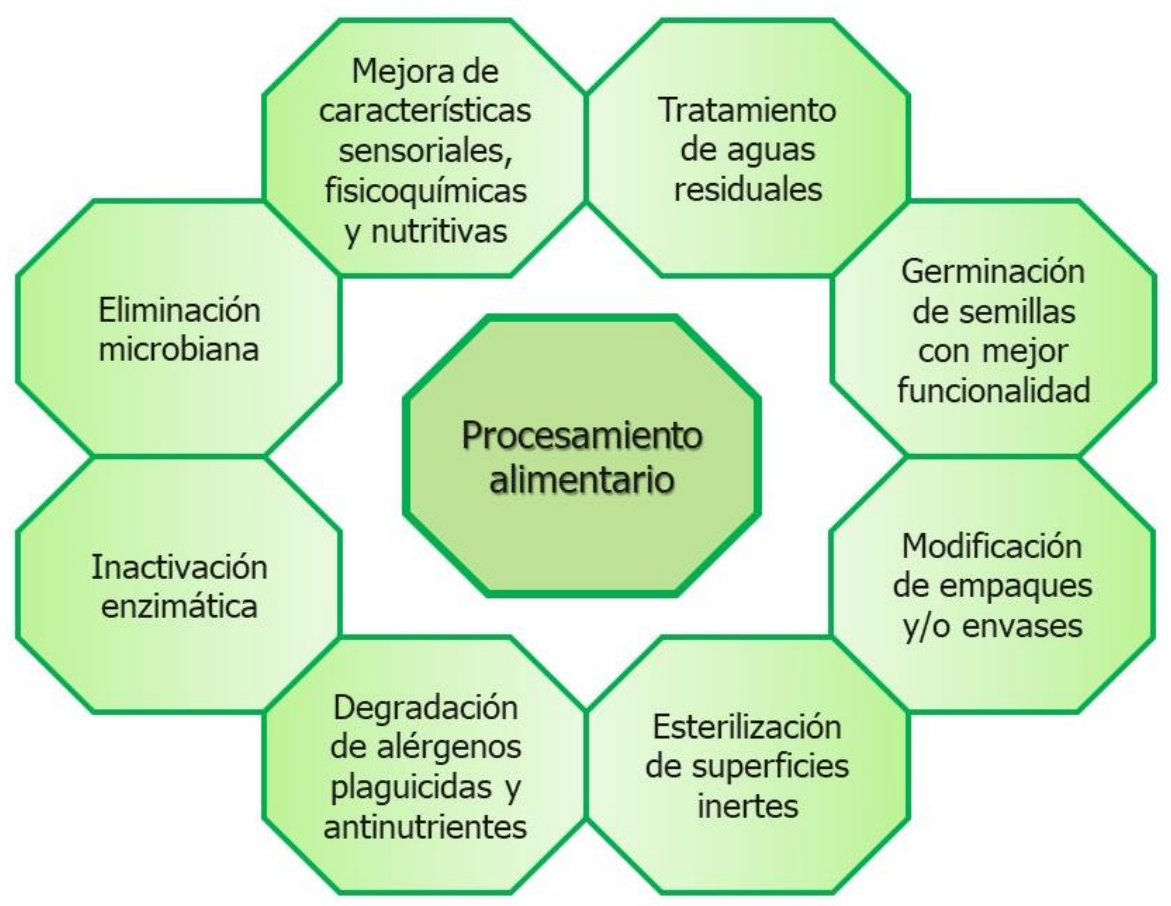

Figura 4. Potenciales aplicaciones del PF en la industria alimentaria.

Nota: El proceso de germinación de semillas fue incluido ya que la producción de germinados, un alimento rico en compuestos bioactivos, está teniendo cada vez más auge.

Aunque el efecto en los atributos sensoriales de los alimentos sea mínimo (Mandal et al., 2018; Pan et al., 2019a), dichas características pueden verse afectadas dependiendo del efecto que tenga el PF con los componentes de la matriz alimentaria, como el pH, proteínas, vitaminas, antocianinas, etc. (Pan et al., 2019a). 
REVISTA DE LA UNIVERSIDAD DEL ZULIA. $3^{a}$ época. Año $12 \mathrm{~N}^{\circ} 32,2021$

Tabla 2. Estudios sobre el efecto del PF en los alimentos y/o compuestos alimentarios.

\begin{tabular}{|c|c|c|c|c|c|}
\hline $\begin{array}{c}\text { Matriz } \\
\text { alimentaria }\end{array}$ & $\begin{array}{c}\text { Gas de } \\
\text { alimentación }\end{array}$ & $\begin{array}{l}\text { Fuente de } \\
\text { plasma }\end{array}$ & $\begin{array}{c}\text { Mejores parámetros } \\
\text { del proceso }\end{array}$ & Principales hallazgos & Referencias \\
\hline Arroz & Aire & DBD & $\begin{array}{c}\mathrm{V}: 20 \mathrm{kV}, \mathrm{HR}: 56 \%, \mathrm{t}: \\
15 \mathrm{~min}\end{array}$ & $\begin{array}{l}\text { Mejora de la hidrofilicidad, energía superficial, } \\
\text { tiempo de cocción, dureza y de la biodisponibilidad } \\
\text { del hierro. Reducción de la dureza, de la humedad } \\
\text { ( } 14.13 \% \text { a } 13.07 \% \text { ) ye la amilosa ( } 25.33 \% \text { a } 19.52 \%) \text {. } \\
\text { Aumento de proteínas }(5.50 \% \text { a } 5.87 \%)\end{array}$ & $\begin{array}{l}\text { Akasapu et } \\
\text { al. (2020) }\end{array}$ \\
\hline $\begin{array}{l}\text { Jugo de naranja } \\
\text { prebiótico }\end{array}$ & Aire & DBD & $\begin{array}{c}\mathrm{V}: 70 \mathrm{kV}, \mathrm{f}: 50 \mathrm{~Hz}, \mathrm{t}: \\
60 \mathrm{~s}\end{array}$ & $\begin{array}{l}\text { Degradación de fructooligosacáridos no } \\
\text { significativa. Mínima diferencia en el valor } L^{*}(0.16) \text {, } \\
<3 \% \text { en el cromático }(0.75) \text { y }<2 \% \text { en el tonal }(1.74) \text {, } \\
\text { lo cual no compromete en la aceptación del } \\
\text { consumidor. Aumento del contenido de ácido } \\
\text { ascórbico (de } 35.10 \pm 0.35 \mathrm{mg} / 100 \mathrm{~mL} \text { a } 41.11 \pm 0.33 \\
\mathrm{mg} / 100 \mathrm{~mL} \text { con exposición directa y } 49.21 \pm 0.88 \\
\mathrm{mg} / 100 \mathrm{~mL} \text { de forma indirecta) y cítrico }(>29 \% \text { con } \\
\text { exposición directa y }>34 \% \text { con exposición indirecta, } \\
\text { aproximadamente. }\end{array}$ & $\begin{array}{l}\text { Almeida et } \\
\text { al. (2017) }\end{array}$ \\
\hline Orujo de tomate & $\begin{array}{c}\text { Aire, Ar, He y } \\
\mathrm{N}_{2}\end{array}$ & DBD & $\begin{array}{c}\mathrm{V}: 60 \mathrm{kV}, \mathrm{f}: 60 \mathrm{~Hz}, \mathrm{t}: \\
15 \mathrm{~min}\end{array}$ & $\begin{array}{l}\text { Disminución del ángulo de contacto con el agua, } \\
\text { acelerando el secado. Incremento de la capacidad } \\
\text { antioxidante, especialmente empleando } \mathrm{N}_{2}(30 \%) \text {. } \\
\text { Aumento del rendimiento de extracción de } \\
\left.\text { compuestos fenólicos en un } 10 \% \text { (con } \mathrm{He}, \mathrm{N}_{2}\right) \text {. }\end{array}$ & $\begin{array}{l}\text { Bao et al. } \\
(2020 a)\end{array}$ \\
\hline Orujo de uva & Aire & DBD & $\begin{array}{c}\mathrm{V}: 60 \mathrm{kV}, \mathrm{f}: 60 \mathrm{~Hz}, \mathrm{t}: \\
15 \mathrm{~min}\end{array}$ & $\begin{array}{l}\text { Reducción del ángulo de contacto con el agua. } \\
\text { Aumento de hasta } 22.8 \% \text { en el rendimiento de } \\
\text { extracción de fenoles (principalmente antocianinas) } \\
\text { y de la capacidad antioxidante hasta } 34.7 \% \text {. }\end{array}$ & $\begin{array}{l}\text { Bao et al. } \\
\text { (2020b) }\end{array}$ \\
\hline $\begin{array}{l}\text { Lechuga de } \\
\text { cordero }\end{array}$ & $\mathrm{O}_{2}$ & $\mathrm{RF}$ & P: 75 y $150 \mathrm{~W}, \mathrm{t}: 120 \mathrm{~s}$ & $\begin{array}{l}\text { Aumento significativo del ácido protocatecuico } \\
(>50 \%) \text {, luteolina (>100\%) y disometina }(>150 \%) \text {. } \\
\text { Incremento de la humectabilidad. }\end{array}$ & $\begin{array}{l}\text { Grzegorzew } \\
\text { ski et al. } \\
\text { (2010) }\end{array}$ \\
\hline
\end{tabular}


REVISTA DE LA UNIVERSIDAD DEL ZULIA. $3^{a}$ época. Año $12 \mathrm{~N}^{\circ} 32,2021$ Vicente Tirado-Kulieva et al. // Análisis crítico del potencial del plasma frío como tecnología ...284-316 DOI: http://dx.doi.org/10.46925//rdluz.32.18

\begin{tabular}{|c|c|c|c|c|c|}
\hline Arándanos & Aire & DBD & $\begin{array}{c}\mathrm{V}: 12 \mathrm{kV}, \mathrm{f}: 5 \mathrm{~Hz}, \mathrm{t}: 60 \\
\mathrm{~s}\end{array}$ & $\begin{array}{l}\text { Reducción de firmeza. Incremento de compuestos } \\
\text { fenólicos totales }(45 \%) \text { y antocianinas }(51 \%) \text { en el } \\
\text { día } 20 \text { de almacenamiento. }\end{array}$ & $\begin{array}{l}\text { Ji et al. } \\
(2020)\end{array}$ \\
\hline $\begin{array}{l}\text { Harina de trigo } \\
\text { duro y blando }\end{array}$ & Aire & $\overline{\mathrm{DBD}}$ & $\mathrm{V}: 70 \mathrm{kV}, \mathrm{t}: 10 \mathrm{~min}$ & $\begin{array}{l}\text { Incremento de la viscosidad y módulo de elasticidad } \\
\text { de la harina de trigo duro. Mejora en la fuerza de la } \\
\text { masa y en el tiempo de mezcla; disminución de la } \\
\text { hoja beta, aumento de la hélice } \alpha \text { y los giros B, en } \\
\text { ambas harinas. }\end{array}$ & $\begin{array}{l}\text { Misra et al. } \\
\quad(2015)\end{array}$ \\
\hline $\begin{array}{l}\text { Proteínas } \\
\text { (hemoglobina, } \\
\text { gelatina de cerdo } \\
\text { y proteína de } \\
\text { pulmón de } \\
\text { bovino) }\end{array}$ & Aire & DBD & $\mathrm{V}: 80 \mathrm{kV} \mathrm{RMS}_{\mathrm{R}}, \mathrm{t}: 15 \mathrm{~min}$ & $\begin{array}{l}\text { Mejoras significativas en las propiedades } \\
\text { funcionales, reológicas y gelificantes, como } \\
\text { solubilidad, capacidad emulsionante, capacidad de } \\
\text { retención de agua y aceite e hidrofobicidad } \\
\text { superficial. }\end{array}$ & $\begin{array}{c}\text { Pérez- } \\
\text { Andrés et al. } \\
(2019)\end{array}$ \\
\hline $\begin{array}{c}\text { Rábano } \\
\text { fermentado } \\
\text { (paocai) }\end{array}$ & Aire & DBD & $\begin{array}{l}\text { V: } 60 \mathrm{kV}, \mathrm{f}: 50 \mathrm{~Hz}, \\
\text { HR: } 45 \%, \mathrm{t}: 60 \mathrm{~s}\end{array}$ & $\begin{array}{l}\text { Mayor consumo de azúcar reductor, aumentando } \\
\text { en } 72.34 \% \text { el contenido de ácido y, por consiguiente, } \\
\text { una reducción del pH (3.98) después de } 7 \text { días. } \\
\text { Reducción de } 48.54 \% \text { de nitritos, } 22.22 \% \text { a } \\
\text { comparación de la pasteurización y de igual manera } \\
\text { en la mejora e incremento de la firmeza y el valor b* } \\
\text { en } 12.53 \% \text { y } 26.26 \% \text {, respectivamente, influenciando } \\
\text { en una reducción del ablandamiento y } \\
\text { oscurecimiento. }\end{array}$ & $\begin{array}{l}\text { Zhao et al. } \\
(2020)\end{array}$ \\
\hline
\end{tabular}

Nota: L* (luminosidad), a* (eje rojo-verde), b* (eje azul-amarillo) = parámetros del espacio de color CIELAB o L*a*b* , empleado como modelo cromático para describir los colores percibidos por el ojo humano. 


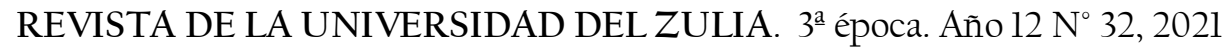

Vicente Tirado-Kulieva et al. // Análisis crítico del potencial del plasma frío como tecnología ...284-316

DOI: http://dx.doi.org/10.46925//rdluz.32.18

Su efecto ha sido demostrado satisfactoriamente en la mejora de las cualidades organolépticas (Hati et al., 2018) y de la funcionalidad del alimento debido al incremento de muchos componentes (Bao et al., 2020a; Bourke et al., 2018; Chizoba et al., 2017; Pérez-Andrés et al., 2019; Sarangapani et al., 2018; Sonawane et al., 2020) como los carbohidratos, proteínas, aminoácidos (Alves et al., 2020), vitaminas como el ácido ascórbico (Almeida et al., 2017), pigmentos como antocianinas (Pérez-Andrés et al., 2019), antioxidantes (Ji et al., 2020) como los compuestos fenólicos (Thirumdas et al., 2016), otros compuestos volátiles (Bourke et al., 2018; Pankaj y Keener, 2017), etc., además, teniendo como objetivo, aumentar su rendimiento (Bao et al., 2020b) y biodisponibilidad (Akasapu et al., 2020; Bao et al., 2020a). Específicamente, con base en Mandal et al. (2018), se ha evidenciado que el PF tiene la capacidad de preservar compuestos bioactivos de interés alimentario y farmacológico, con resultados efectivos en el ácido ascórbico, glutatión, $\alpha$-tocoferol, $\beta$-caroteno y flavonoides, logrando conservar especialmente la actividad antioxidante del alimento.

El ablandamiento es un problema común relacionado a la textura del alimento, repercutiendo en su calidad (Pan et al., 2020 y por ello, el PF se plantea como alternativa para mejorar las propiedades texturales, comprobándose su eficacia en legumbres, cereales (Thirumdas et al., 2016), otros granos y también en masa de pan (Hati et al.,2018). El almidón, uno de los ingredientes y compuestos alimentarios más importantes, tiene influencia directa en la textura de los productos y por eso, debe asegurarse su correcta funcionalidad y vida útil, especialmente del nativo el cual es más susceptible a causa de diversas limitaciones como su insolubilidad en frío, el tener una rápida retrogradación (Thirumdas et al., 2017), además de pérdida de viscosidad y de espesamiento al finalizar el proceso de cocción. Thirumdas y Sarangapani (2015) afirman que el PF puede aplicarse como aditivo para solucionar las deficiencias del almidón nativo, produciéndole cambios deseables. De acuerdo con Mandal et al. (2018) eso se debe al efecto de las ER del PF y que, según Thirumdas et al. (2017), afectan su estructura químicamente mediante el aumento de energía, integración de grupos funcionales, despolimerización e incluso actúan como agentes reticulantes, repercutiendo en mejoras en el poder de hinchamiento, solubilidad, absorción de agua, características de pegado y especialmente, la resistencia en condiciones en adversas. 


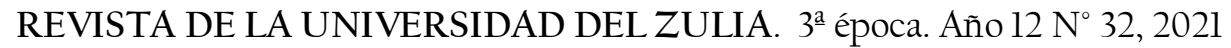

Vicente Tirado-Kulieva et al. // Análisis crítico del potencial del plasma frío como tecnología ...284-316

DOI: http://dx.doi.org/10.46925//rdluz.32.18

Al igual que en el almidón, Pérez-Andrés et al. (2019) señalan que el PF tiene un efecto similar en las proteínas, ya que a partir de las modificaciones que ocasiona en su estructura, se producen cambios positivos y significativos en sus propiedades funcionales, gelificantes y reológicas. Asimismo, se concluyó que el impacto dependía de la naturaleza nativa de la proteína.

De la misma forma, ha sido aplicado en subproductos agroindustriales, como los resultantes del procesamiento del tomate (Bao et al., 2020a) y la uva (Bao et al., 2020b), dándoles un valor agregado a los usualmente considerados como residuos y también reducir la contaminación ambiental que representan debido a su descomposición.

Al probarse experimentalmente el potencial del PF en la calidad alimentaria, es conveniente perfeccionar la técnica individual para poder desarrollar una combinada con otras tecnologías para obtener resultados más óptimos.

\subsection{Envases de alimentos y biopolímeros de recubrimiento}

Los materiales de envasado son muy empleados en la industria alimentaria. Los más usados para productos frescos perecederos son el ácido poliláctico (PLA), el tereftalato de polietileno (PET) de baja y alta densidad, el polipropileno (PP), el polietileno (PE) y vidrio (Feizollahi et al., 2020; Pan et al., 2019a). Estos se emplean para mantener la calidad del producto al protegerlo de la contaminación u otro tipo de daño exterior durante su manipulación, transporte y almacenamiento y por ello, si no se encuentran en condiciones óptimas microbiológicamente, pueden contaminarse y de igual manera los alimentos, ocasionando pérdidas económicas y daños en la salud (Misra et al., 2011; Pankaj et al., 2014; Thirumdas y Sarangapani, 2015).

Con el objetivo de descontaminar los envases alimentarios, sin afectar a los productos, se propone al PF como técnica alentadora para sustituir las tecnologías y tratamientos convencionales (Chizoba et al., 2017; Kaluwahandi et al., 2020; Mandal et al., 2018; Misra et al., 2011; Munekata et al., 2020; Pankaj et al., 2014; Pankaj y Keener, 2017; Sonawane et al., 2020), especialmente para el material de embalaje sensible a altas temperaturas (Bourke et al., 2018; Mandal et al., 2018; Oh et al., 2016;) como el PET y el policarbonato (Thirumdas y Sarangapani et al., 2015), siendo económico, atóxico, sin causar efectos secundarios en el envase ni en el alimento y sin dejar residuos (Hati et 


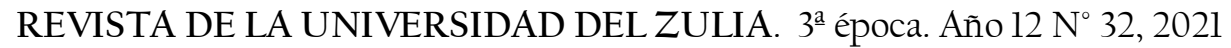

Vicente Tirado-Kulieva et al. // Análisis crítico del potencial del plasma frío como tecnología ...284-316

DOI: http://dx.doi.org/10.46925//rdluz.32.18

al., 2018; Pan et al., 2019a; Pankaj et al., 2014; Pankaj y Thomas, 2016; Scholtz et al., 2015; Thirumdas y Sarangapani, 2015). Incluso, según Pankaj y Thomas (2016), el PF es tan efectivo al igual que una correcta esterilización, ya que evita la recontaminación posterior al tratamiento.

También ofrece la capacidad de modificar las cualidades del empaque o integrar nuevas funcionalidades específicas de interés (Kaluwahandi et al., 2020; Mandal et al., 2018; Oh et al., 2016; Pan et al., 2019a; Pan et al., 2019b; Pankaj y Thomas, 2016; Sarangapani et al., 2018; Thirumdas y Sarangapani, 2015), como, por ejemplo, en el aumento de la energía superficial, mejorando la humectabilidad e hidrofobicidad (Scholtz et al., 2015), también para mejorar la imprimibilidad, adhesión o antiadhesión, la resistencia a fallos mecánicos (Pankaj et al., 2014), las características de barrera y sellado, reduciendo la pentración de $\mathrm{O}_{2}, \mathrm{CO}_{2}$ y vapor de agua (Pan et al., 2019a; Pankaj et al., 2014), y contaminantes no deseables, (Hati et al., 2018). Asímismo, además de los envases comunes, el PF muestra potencial de aplicación en materiales de empaque activos e inteligentes (Pankaj et al., 2014), en películas y recubrimientos comestibles (Mandal et al., 2018; Pankaj y Thomas, 2016; Thirumdas y Sarangapani, 2015).

Las ER del PF encargadas de los cambios en el envase (Munekata et al., 2020), intervienen en la generación de grupos polares o reticulación de las moléculas y por ello se da la activación de la superficie (Pan et al., 2019a). Además, Hati et al. (2018) plantean que otro mecanismo de acción de las especies es por su efecto en la sustracción o adición de grupos funcionales de la composición del empaque, logrando influir de forma directa en las propiedades antimicrobianas y mecánicas como la absorción, sellado y adhesión.

Uno de los estudios que demostró el gran potencial del PF es, por ejemplo, el de Oh et al. (2016) sobre su efecto en las características físicas de la harina de soja desgrasada (y glicerol en proporción 10:3) empleada como película en el envasado de salmón ahumado, usando diversos gases como $\mathrm{O}_{2}, \mathrm{~N}_{2}, \mathrm{He}$, Ar y aire, con una potencia de $400 \mathrm{~W}$, por $15 \mathrm{~min}$. En los mejores resultados se logró el aumento de la resistencia a la tracción (6.8\%), elongación (13.4\%) y la propiedad de barrera (24.4\%). Además, se comprobó que, con la adición de la película, la oxidación lipídica era más lenta y en el salmón, su dureza duraba por más tiempo. 


\subsection{Tratamiento de aguas residuales}

En la industria de los alimentos, el agua es de vital importancia al emplearse en gran volumen para el procesamiento de los alimentos, para los procesos térmicos, la limpieza y lavado de las zonas y equipos, etc. A causa de su enorme consumo, de igual manera se generan las aguas residuales, las cuales están compuestas de materia orgánica en gran proporción como carbohidratos, proteínas, grasas, vitaminas y minerales (Chizoba et al., 2017; Hati et al., 2018; Jiang et al., 2016; Patange et al., 2018) y que, si no son tratadas, pueden representar un riesgo microbiológico (Hati et al., 2018; Sarangapani et al., 2018), afectando el ambiente y, por consiguiente, la salud de los seres vivos.

A causa de la composición de los efluentes, se requiere de tecnologías complejas para su tratamiento (Chizoba et al., 2017; Sarangapani et al., 2018), siendo las más utilizadas el procesamiento aeróbico y anaeróbico, la electroquímica, ultrafiltración, cloración, radiación, osmosis inversas, entre otras (Jiang et al., 2016; Patange et al., 2018). Estas, además de ser costosas y requerir altos niveles de energía, no logran una completa purificación.

El PF emerge como opción tecnológica viable y efectiva para el tratamiento de contaminantes acuosos (Sarangapani et al., 2018) que ya ha sido probada en efluentes del procesamiento de tomates, remolachas, palmas datileras y moras, en los que, en la investigación de Mohamed et al. (2016), empleando Ar con un flujo de $4.5 \mathrm{~L} / \mathrm{min}$ y por 90 s, se logró la descontaminación de Escherichia coli, Shigella boydii, Enterococcus faecalis, Pseudomonas aeruginosa y Campylobacter jejuni, obteniendo mejores resultados en la reducción desde $7 \log _{10} \mathrm{UFC} / \mathrm{ml}$ a $1.4 \log _{10} \mathrm{UFC} / \mathrm{ml}$ para E. coli, y el más bajo a $3.34 \log _{10}$ $\mathrm{UFC} / \mathrm{ml}$ para S. boydii. De igual forma se evaluó la reducción de endotoxinas, logrando en $180 \mathrm{~s}$, el $90.22 \%$ en las aguas residuales del procesamiento de la palma datilera, $75.84 \%$ en las del tomate, $69.83 \%$ en las de la remolacha y $54.84 \%$ en las de la mora. También se analizó las características físicas y químicas empleando $\mathrm{Ar}+0.2 \%$ de $\mathrm{O}_{2}$, obteniendo reducciones significativas del $\mathrm{pH}$, sólidos suspendidos totales, proteínas y azúcares totales, carbono orgánico total y demanda química de oxígeno. 
REVISTA DE LA UNIVERSIDAD DEL ZULIA. $3^{a}$ época. Año $12 \mathrm{~N}^{\circ}$ 32, 2021 Vicente Tirado-Kulieva et al. // Análisis crítico del potencial del plasma frío como tecnología ...284-316 DOI: http://dx.doi.org/10.46925//rdluz.32.18

Igualmente, en efluentes de productos lácteos y cárnicos, Patange et al. (2018) demostraron en que el tratamiento con PF dependientemente del tiempo, lograba una reducción significativa de patógenos comunes como Escherichis coli, Enterococcus faecalis, Clostridium perfringens y Bacillus megaterium y también, se obtuvo una alta disminución (>2 ciclos logarítmicos) de las endosporas de B. megaterium. Asimismo, evaluando el impacto ecotoxicológico después de $24 \mathrm{~h}$, las muestras tratadas tenían menor efecto negativo en los modelos acuáticos (células de peces RTG-2 y PLHC-1 y crustáceo Daphnia magna), pero aún así, se mostró sensibilidad, siendo mayor en las células en efluentes cárnicos. Según este último resultado, es recomendable analizar la toxicidad del PF en otros organismos acuáticos de interés.

Para tener un breve entendimiento del mecanismo de acción de las ER del PF en la descontaminación de las aguas residuales procedentes del procesamiento alimentario, según la información de Chizoba et al. (2017), enfocándose en las ERO, su bombardeo genera producto de la interacción de los radicales $\mathrm{OH}$ y la energía de la radiación UV en conjunto, un daño térmico y químico de alta intensidad a los agentes contaminantes.

Con respecto a la precosecha y cosecha de la materia prima, se da en gran cantidad el uso de plaguicidas sintéticos que permanecen sin degradarse, hasta en las aguas residuales. Jiang et al. (2016) mencionan que los compuestos fenólicos son comúnmente empleados en la producción de los plaguicidas y por consecuente, se suelen encontrarse en los efluentes. En su estudio indicaron de manera resumida que, gracias a las reacciones oxidantes de los radicales $\mathrm{OH}$ del $\mathrm{PF}$ que atacan electrofísicamente a los fenoles, causando su degradación por hidroxilación.

\section{Desafíos y tendencias futuras}

Aunque el potencial del PF ha tenido excelentes resultados y muy prometedores en el campo alimentario, aún tiene pocos años de estudio y aplicación, por lo cual es usual que se presenten ciertos inconvenientes como, por ejemplo, Gavahian et al. (2018); Liao et al. (2020) sostienen que una exposición larga del PF podría inducir a la peroxidación lipídica de los alimentos con un alto porcentaje de grasas, lo cual afectaría 
gravemente su calidad. De igual manera, según la investigación de Hati et al. (2018), se han mostrado

Hay pocos estudios relacionados a la aplicación del PF en la reducción o eliminación de parásitos, los cuales, al igual que los demás microbios, son agentes que pueden infectar al alimento y causar ETAs. Considerando la eficiencia del PF como descontaminante, es conveniente realizar experimentaciones para probar su efecto en los parásitos y disminuir el impacto que ocasionan a la seguridad alimentaria.

Se ha demostrado su efecto del PF en la inactivación de enzimas indeseables, pero también en diversos estudios se comprobó que influía en el aumento de la actividad de ciertas enzimas deseables (en la mayoría de casos), lo cual significa un gran reto para la industria el realizar más investigaciones para tener mayor comprensión del proceso y poder adecuar el potencial de la técnica para que solamente inhiba a las que causan daño en los alimentos y a la vez, potencie las enzimas deseables.

Lo más importante y preocupante es que el PF al ser una tecnología compleja, al interactuar con la matriz alimentaria directa o indirectamente (a través del empaque), puede ocasionar diversas reacciones químicas que afecten negativamente en la composición, pudiendo ocasionar alteraciones indeseables y hasta destruir los compuestos benéficos. Por ejemplo, según la investigación de Hati et al. (2018), se han observado casos de ablandamiento y pardeamiento en algunas frutas. Para comprender mejor la tecnología del PF, es fundamental analizar las especies reactivas generadas, sus mecanismos de acción precisos y los distintos resultados obtenidos en sus aplicaciones. Además, Pan et al. (2019b) sugieren que posterior a la aplicación, se evalue la posible creación de subproductos tóxicos.

\section{Conclusiones}

En los últimos años ha incrementado el tratamiento de los alimentos con PF, obteniendo óptimos resultados, convirtiéndolo en una tecnología no destructiva idónea que aún tiene mucho potencial por explotar. Según la información recopilada, hay muchas fuentes para generar PF y que combinado al tipo de gas usado y los distintos parámetros de operación, se obtienen las características únicas de sus ER, responsables de la actividad antimicrobiana contra principales patógenos como E. coli, L. 


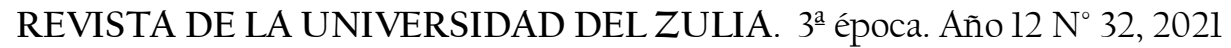

Vicente Tirado-Kulieva et al. // Análisis crítico del potencial del plasma frío como tecnología ...284-316

DOI: http://dx.doi.org/10.46925//rdluz.32.18

monocytogenes y Salmonella spp, de su actividad inhibidora de enzimas indeseables como LPS, PFO y POX, de su capacidad para mantener y hasta potenciar la calidad del alimento, causando efecto directo o también de forma indirecta, en su empaque. Asimismo, se comprobó que sus propiedades pueden ser aprovechadas en el tratamiento de los efluentes acuosos, un problema que afecta a todas las industrias. En términos generales, se destaca la capacidad del PF en el procesamiento alimentario, sin embargo, es conveniente realizar más estudios para ampliar el conocimiento sobre todo lo relacionado a su aplicación en la industria.

\section{Referencias}

Adebo, O., Molelekoa, T., Makhuvele, R., Adebiyi, J., Oyedeji, A., Gbashi, S., Adefisoye, M., Ogundele, O. \& Njobeh, B. (2020). A review on novel non-thermal food processing techniques for mycotoxin reduction. International Journal of Food Science \& Technology. https://doi.org/10.1111/ijfs.14734

Akasapu, K., Ojah, N., Kumar, A., Jyoti, A. \& Mishra, P. (2020). An innovative approach for iron fortification of rice using cold plasma. Food Research International. https://doi.org/10.1016/j.foodres.2020.109599

Alkawareek, M.Y., Gorman, S.P., Graham, W.G. \& Gilmore, B.F. (2014). Potential cellular targets and antibacterial efficacy of atmospheric pressure non-thermal plasma. International Journal of Antimicrobial Agents, 43(2), 154-160

Almeida, F.D.L., Gomes, W.F., Cavalcante, R.S., Tiwari, B.K., Cullen, P.J., Frias, J.M., Bourke, P., Fernandes, F.A.N. \& Rodrigues, S. (2017). Fructooligosaccharides integrity after atmospheric cold plasma and highpressure processing of a functional orange juice. Food Research International, 102, 282-290

Alves, E., Brito, E. \& Rodrigues, S. (2020). Effects of cold plasma processing in food components. In: D. Bermúdez-Aguirre (Ed.), Advances in Cold Plasma Applications for Food Safety and Preservation (253-268). Massachusetts: Academic Press

Annapure, U.S. (2018). Application of Cold Plasm in Food Processing. In: Sharma, HK y Panesar, PS. (Ed.), Technologies in Food Processing (25-46). Massachusetts: Academic Press

Baggio, A., Marino, M., Innocente, N., Celotto, M. \& Maifreni, M. (2020). Antimicrobial efect of oxidative technologies in food processing: an overview. European Food Research and Technology, 246, 669-692

Baier, M., Gorgen, M., Ehlbeck, J., Knorr, D., Herppich, W. \& Schlüter, O. (2014). Nonthermal atmospheric pressure plasma: Screening for gentle process conditions and 


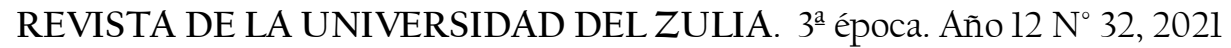

Vicente Tirado-Kulieva et al. // Análisis crítico del potencial del plasma frío como tecnología ...284-316

DOI: http://dx.doi.org/10.46925//rdluz.32.18

antibacterial efficiency on perishable fresh produce. Innovative Food Science and Emerging Technologies, 22, 147-157

Bao, Y., Reddivari, L. \& Huang, J.Y. (2020a). Development of cold plasma pretreatment for improving phenolics extractability from tomato pomace. Innovative Food Science and Emerging Technologies, 65, 102445

Bao, Y., Reddivari, L. \& Huang, J.Y. (2020b). Enhancement of phenolic compounds extraction from grape pomace by high voltage atmospheric cold plasma. LWT - Food Science and Technology, 133, 109970

Bermúdez-Aguirre, D., Wemlinger, D., Pedrow, P., Barbosa-Cánovas, G. \& GarciaPerez, M. (2013). Effect of atmospheric pressure cold plasma (APCP) on the inactivation of Escherichia coli in fresh produce. Food Control, 34(1), 149-157

Bourke, P., Ziuzina, D., Boehm, D., Cullen, P.J. \& Keener, K. (2018). The Potential of Cold Plasma for Safe and Sustainable Food Production. Trends in Biotechnology, 36(6), 615-626

Bourke, P., Ziuzina, D., Han, L., Cullen, P.J. \& Gilmore, B.F. (2017). Microbiological Interactions with Cold Plasma. Journal of Applied Microbiology, 123(2), 308-324

Charoux, C.M.G., Patange, A., Lamba, S., O'Donnell, C.P., Tiwari, B.K. \& Scannell, A.G.M. (2020). Applications of nonthermal plasma technology on safety and quality of dried food ingredients. Journal of Applied Microbiology. https://doi.org/10.1111/jam.14823

Chen, Y.Q., Cheng, J.H. \& Sun, D.W. (2019). Chemical, physical and physiological quality attributes of fruit and vegetables induced by cold plasma treatment: Mechanisms and application advances. Critical Reviews in Food Science and Nutrition, 60 (16), 2676-2690

Cheng, J.H., Xiaoye, L.V., Yuanyuan, P. \& Sun, D.W. (2020). Foodborne bacterial stress responses to exogenous reactive oxygen species (ROS) induced by cold plasma treatments. Trends in Food Science \& Technology, 103, 239-247

Chizoba, F.G., Sun, D.W. \& Cheng, J.H. (2017). A review on recent advances in cold plasma technology for the food industry: Current applications and future trends. Trends in Food Science \& Technology, 69(A), 46-58

Coutinho, N.M., Silveira, M.R., Rocha, R.S., Moraes, J., Ferreira, M.V.S., Pimentel, T.C., Freitas, M.Q., Silva, M.C., Raices, R.S.L., Ranadheera, C.S., Borges, F.O., Mathias, S.P., Fernandes, F.A.N., Rodrigues, S. \& Cruz, A.G. (2018). Cold plasma processing of milk and dairy products. Trends in Food Science \& Technology, 74, 56-68

Feizollahi, E., Misra, N.N. \& Roopesh, M.S. (2020). Factors influencing antimicrobial efficacy of Dielectric Barrier Discharge (DBD) Atmospheric Cold Plasma (ACP) in food 


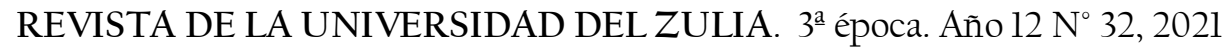

Vicente Tirado-Kulieva et al. // Análisis crítico del potencial del plasma frío como tecnología ...284-316

DOI: http://dx.doi.org/10.46925//rdluz.32.18

processing applications. Critical Reviews in Food Science and Nutrition. https://doi.org/10.1080/10408398.2020.1743967

Fellows, P.J. (2016). Food Processing Technology: Principles and Practice. United Kingdom: Woodhead Publishing

Fridman, A. (2008). Plasma chemistry. New York: Cambridge University Press

Gavahian, M. \& Khaneghah, A.M. (2020). Cold plasma as a tool for the elimination of food contaminants: Recent advances and future trends. Critical Reviews in Food Science and Nutrition, 60(9), 1581-1592

Gavahian, M., Chu, Y.H., Khaneghah, A.M., Barba, F.J. \& Misra, N.N. (2018). A critical analysis of the cold plasma induced lipid oxidation in foods. Trends in Food Science \& Technology, 77, 32-41

Grzegorzewski, F., Rohn, S., Kroh, L.W., Geyer, M. \& Schlüter, O. (2010). Surface morphology and chemical composition of lamb's lettuce (Valerianella locusta) after exposure to a low -pressure oxygen plasma. Food Chemistry, 122(4), 1145-1152

Han, Y., Cheng, J.H. \& Sun, DW. (2019)._Activities and conformation changes of food enzymes induced by cold plasma: A review. Critical Reviews in Food Science and Nutrition, 59(5), 794-811

Hati, S., Patel, M. \& Yadav, D. (2018). Food bioprocessing by nonthermal plasma technology. Current Opinion in Food Science, 19, 85-91

Ji, Y., Hu, W., Liao, J., Jiang, A., Xiu, Z., Gaowa, S., Guan, Y., Yang, X., Feng, K. \& Liu, C. (2020). Effect of atmospheric cold plasma treatment on antioxidant activities and reactive oxygen species production in postharvest blueberries during storage. Journal of the Science of Food and Agriculture. https://doi.org/10.1002/jsfa.10611

Jiang, B., Zheng, J. \& Wu, M. (2016). Nonthermal Plasma for Effluent and Waste Treatment. In: Misra NN, Schlüter, O. y Cullen PJ. (Ed.), Cold Plasma in Food and Agriculture (309-342). Massachusetts: Academic Press

Kaluwahandi, N., Wei, L. \&Muthukumarappan, K. (2020). Opportunities and Challenges of Cold Plasma in Food Processing. American Society of Agricultural and Biological Engineers (ASABE) Annual International Virtual Meeting 2000969. https://doi.org/10.13031/aim.202000969

Khani, M.R., Shokri, B. \& Khajeh, K. (2017). Studying the Performance of Dielectric Barrier Discharge and Gliding Arc Plasma Reactors in Tomato Peroxidase Inactivation. Journal of Food Engineering, 197, 107-112

Kim, J.E., Lee, D.U. \& Min, S.C. (2014). Microbial decontamination of red pepper powder by cold plasma. Food Microbiology, 38, 128-136 


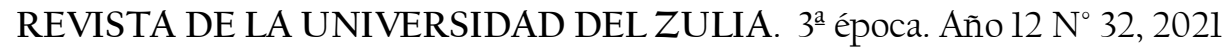

Vicente Tirado-Kulieva et al. // Análisis crítico del potencial del plasma frío como tecnología ...284-316

DOI: http://dx.doi.org/10.46925//rdluz.32.18

Kim, J.E., Oh, Y.J., Won, M.Y. \& Min, S.C. (2017). Microbial decontamination of onion powder using microwave-powered cold plasma treatments. Food Microbiology, 62, $112-123$

Lacombe, A., Niemira, B.A., Gurtler, J.B., Fan, X., Sites, J., Boyd, G. \& Chen, H. (2015). Atmospheric Cold Plasma Inactivation of Aerobic Microorganisms on Blueberries and Effects on Quality Attributes. Food Microbiology, 46, 479-484

Li, N., Yu, J.J., Jin, N., Chen, Y., Li, S.H. \& Chen, Y. (2020). Modification of the physicochemical and structural characteristics of zein suspension by dielectric barrier discharge cold plasma treatment. Journal of Food Science, 84(8), 2452-2460

Liao, X., Cullen, P.J., Muhammad, A.D., Jiang, Z., Ye, X., Liu, D. \& E Ding, T. (2020). Cold Plasma-Based Hurdle Interventions: New Strategies for Improving Food Safety. Food Engineering Reviews, 12, 321-332

Liao, X., Liu, D., Xiang, Q., Ahn, J., Chen, S., Ye, X., \& Ding, T. (2017). Inactivation mechanisms of non-thermal plasma on microbes: A review. Food Control, 75, 83-91.

Lieberman, M. \& Lichtenberg, A. (2005). Principles of plasma discharges and materials processing. Hoboken: John Wiley \& Sons

Lunov, O., Churpita, O., Zablotskii, V., Deyneka, I.G., Meshkovskii, I.K., Jäger, A., Syková, E., Kubinová, S. \&e Dejneka, A. (2015). Non-thermal plasma mills bacteria: scanning electron microscopy observations. Applied Physics Letters, 106(5), 053703

Mandal, R., Singh, A. \& Singh, A.P. (2018). Recent developments in cold plasma decontamination technology in the food industry. Trends in Food Science \& Technology, 80, 93-103

Mir, S.A., Siddiqui, M.W., Dar, B.N., Shah, M.A., Wani, M.H., Roohinejad, S., Annor, G.A., Mallikarjunan, K., Chin, C.F. \& Ali, A. (2020). Promising applications of cold plasma for microbial safety, chemical decontamination and quality enhancement in fruits. Journal of Applied Microbiology, 129(3), 474-485

Misra, N.N., Kaur, S., Tiwari, B., Kaur, A., Singh, N. \&\& Cullen, P.J. (2015). Atmospheric pressure cold plasma (ACP) treatment of wheat flour. Food Hydrocolloids, 44, 115-121

Misra, N.N., Pankaj, S.K., Segat, A. \& Ishikawa, K. (2016). Cold plasma interactions with enzymes in foods and model systems. Trends in Food Science \& Technology, 55, $39-47$

Misra, N.N., Patil, S., Moiseev, T., Bourke, P., Mosnier, J.P., Keener, K.M. \& Cullen, P.J. (2014). In-package atmospheric pressure cold plasma treatment of strawberries. Journal of Food Engineering, 125, 131-138

Misra, N.N., Tiwari, B.K., Raghavarao, K.S.M.S. \& Cullen, P.J. (2011). Nonthermal plasma inactivation of food-borne pathogens. Food Engineering Reviews, 3, 159-170 


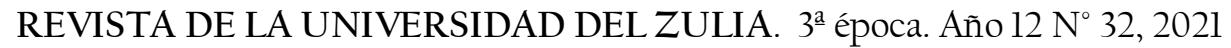

Vicente Tirado-Kulieva et al. // Análisis crítico del potencial del plasma frío como tecnología ...284-316

DOI: http://dx.doi.org/10.46925//rdluz.32.18

Misra, N.N., Yadav, B., Roopesh, M.S. \& Jo, C. (2018). Cold Plasma for Effective Fungal and Mycotoxin Control in Foods: Mechanisms, Inactivation Effects, and Applications. Comprehensive Reviews in Food Science and Food Safety, 18, 106-120

Misra, N.N., Yepez, X. \& Keener, K. (2019). In-package cold plasma technologies. Journal of Food Engineering, 244, 21-31

Mohamed, A.A., Al Shariff, S.M., Ouf, S.A., \& Benghanem, M. (2016). Atmospheric pressure plasma jet for bacterial decontamination and property improvement of fruit and vegetable processing wastewater. Journal of Physics D: Applied Physics, 49(19), 195401

Mostafidi, M., Reza, M., Shirkhan, S. \& Z Zahedi, M.T. (2020). A review of recent trends in the development of the microbial safety of fruits and vegetables. Trends in Food Science \& Technology, 103, 321-332

Munekata, P.E.S., Domínguez, R., Peteiro, M. \& Lorenzo, J.M. (2020). Influence of Plasma Treatment on the Polyphenols of Food Products-A Review. Foods, 9(7), 929

Niemira, B.A. (2012). Cold Plasma Decontamination of Foods. Annual Review of Food Science and Technology, 3, 125-142

Niemira, B.A. (2014). Decontamination of Foods by Cold Plasma. In: DW Sun (Ed.), Emerging Technologies for Food Processing (323-333). Massachusetts: Academic Press

Niemira, B.A. \& Sites, J. (2008). Cold plasma inactivates Salmonella Stanley and Escherichia coli O157:H7 inoculated on golden delicious apples. Journal of Food protection, $71(7)$, 1357-1365

Oh Y.A., Roh S.H. \& Min, S.C. (2016). Cold plasma treatments for improvement of the applicability of defatted soybean meal-based edible film in food packaging. Food Hydrocolloids, 58, 150-159

Ozen, E. \& Singh, R.K. (2020). Atmospheric cold plasma treatment of fruit juices: A review. Trends in Food Science \& Technology, 103, 144-151

Pan, Y., Cheng, J.H. \& Sun, D.W. (2019a). Cold Plasma-Mediated Treatments for Shelf Life Extension of Fresh Produce: A Review of Recent Research Developments. Comprehensive Reviews in Food Science and Food Safety, 18(5), 1312-1326

Pan, Y., Zhang, Y., Cheng, J.H. \&\&Sun, D.W. (2019b). Inactivation of Listeria Monocytogenes at various growth temperatures by ultrasound pretreatment and cold plasma. LWT - Food Science and Technology, 118, 108635

Pan, Y.W., Cheng, J.H. \& Sun, D.W. (2020). Inhibition of fruit softening by cold plasma treatments: affecting factors and applications. Critical Reviews in Food Science and Nutrition. https://doi.org/10.1080/10408398.2020.1776210 


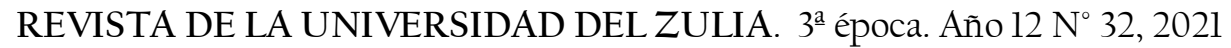

Vicente Tirado-Kulieva et al. // Análisis crítico del potencial del plasma frío como tecnología ...284-316

DOI: http://dx.doi.org/10.46925//rdluz.32.18

Pankaj S.K \& Thomas, S. (2016). Cold Plasma Applications in Food Packaging. In: Misra NN, Schlüter, O. y Cullen PJ. (Ed.), Cold Plasma in Food and Agriculture (293307). Massachusetts: Academic Press

Pankaj, S.K. \& Keener, K.M. (2017). Cold plasma: background, applications and current trends. Current Opinion in Food Science, 16, 49-52

Pankaj, S.K., Bueno-Ferrer, C., Misra, N.N., Milosavljevic, V., O’Donnel, C.P., Bourke, P., Keener, K.M. \& Cullen, P.J. (2014). Applications of cold plasma technology in food packaging. Trends In Food Science \& Technology, 35, 5-17

Pankaj, S.K., Misra, N.N. \& Cullen, P.J. (2013). Kinetics of tomato peroxidase inactivation by atmospheric pressure cold plasma based on dielectric barrier discharge. Innovative Food Science and Emerging Technologies, 19, 153-157

Pankaj, S.K., Wan, Z. \& Keener, K.M. (2018). Effects of Cold Plasma on Food Quality: A Review. Foods, 7(1), 4

Pasquali, F., Stratakos, A.C., Koidis, A., Berardinelli, A., Cevoli, C., Ragni, L., Mancusi, R., Manfreda, G. \& Trevisani, M. (2016)._Atmospheric cold plasma process for vegetable leaf decontamination: A feasibility study on radicchio (red chicory, Cichorium intybus L.). Food Control, 60, 552-559

Patange, A., Boehm, D., Giltrap, M., Lu, P., Cullen, P.J. \& Bourke, P. (2018). Assessment of the disinfection capacity and eco-toxicological impact of atmospheric cold plasma for treatment of food industry effluents. Science of the Total Environment, 631-632, 298-307

Patil, S., Bourke, P. \& Cullen P.J. (2016). Principles of Nonthermal Plasma Decontamination. In: Misra NN, Schlüter, O. y Cullen PJ. (Ed.), Cold Plasm in Food and Agriculture (143-177). Massachusetts: Academic Press

Pérez-Andrés, J.M., Álvarez, C., Cullen, P.J. \& Tiwari, B. (2.K019). Effect of cold plasma on the techno-functional properties of animal protein food ingredients. Innovative Food Science and Emerging Technologies, 58, 102205

Phan, K.T.K., Phan, H.T., Brennan, C.S. \& Phimolsiripol, Y. (2017). Nonthermal plasma for pesticide and microbial elimination on fruits and vegetables: an overview. International Journal of Food Science and Technology, 52(10), 2127, 2137

Pinela, J. \& Ferreira, I.C.F.R. (2017). Non-thermal Physical Technologies to Decontaminate and Extend the Shelf-life of Fruits and Vegetables: Trends Aiming at Quality and Safety. Critical Reviews in Food Science and Nutrition, 57(10), 2095-21ll

Sarangapani, C., Patange, A., Bourke, P., Keener, K. \& Cullen, P.J. (2018). Recent Advances in the Application of Cold Plasma Technology in Foods. Annual Review of Food Science and Technology, 9, 609-629 


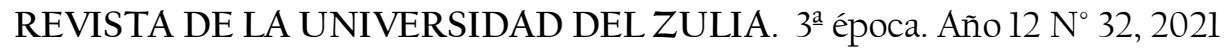

Vicente Tirado-Kulieva et al. // Análisis crítico del potencial del plasma frío como tecnología ...284-316

DOI: http://dx.doi.org/10.46925//rdluz.32.18

Schlüter, O., Ehlbeck, J., Hertel, C., Habermeyer, C., Roth, A., Engel, KH., Holzhauser, T., Knorr, D. \& Eisenbrand, G. (2013). Opinion on the use of plasma processes for treatment of foods. Molecular Nutrition Food Research, 57(5), 920-927

Scholtz, V., Pazlarova, J., Souskova, H., Khun J. \& Julak J. (2015). Nonthermal plasma - A tool for decontamination and disinfection. Biotechnology Advances, 33(6), 11081119

Selcuk, M., Oksuz, L. \& Basaran, P. (2008). Decontamination of grains and legumes infected with Aspergillus spp. and Penicillum spp. by cold plasma treatment. Bioresource Technology, 99(11), 5104-5109

Sonawane, S. y Marar, T. \& Patil, S. (2020). Non-thermal plasma: An advanced technology for food industry. Food Science and Technology International, 26(8), 727740

Stoica, M., Alexe, P. \& Mihalcea, L. (2014). Atmospheric cold plasma as new strategy for foods processing-an overview. Innovative Romanian Food Biotechnology, 15, 1-8

Surowzky, B., Fischer, A., Schlueter, O. \& Knorr, D. (2013). Cold plasma effects on enzyme activity in a model food system. Innovative Food Science and Emerging Technologies, 19, 146-152

Surowzky, B., Frohling, A., Gottschalk, N., Schlüter, O. \& Knorr, D. (2014). Impact of cold plasma on Citrobacter freundii in apple juice: Inactivation kinetics and mechanisms. International Journal of Food Microbiology, 174, 63-71

Thirumdas, R., Kadam, D. \& Annapure, U.S. (2017). Cold Plasma: an Alternative Technology for the Starch Modification. Food Biophysics, 12, 129-139

Thirumdas, R., Saragapani, C., Ajinkya, M.T., Deshmukh, R.R. \& Annapure, U.S. (2016). Influence of low pressure cold plasma on cooking and textural properties of brown rice. Innovative Food Science and Emerging Technologies, 37(A), 53-60

Thirumdas, R., Sarangapani, C. \& Annapure, U.S. (2015). Cold Plasma: A novel NonThermal Technology for Food Processing. Food Biophysics, 10, 1-11

Zhao, N., Ge, L., Huanga, Y., Wang, Y., Wang, Y., Lai, H., Wang, Y., Zhua, Y. \& Zhang, J. (2020). Impact of cold plasma processing on quality parameters of packaged fermented vegetable (Radish paocai) in comparison with pasteurization processing: Insight into safety and storage stability of products. Innovative Food Science and Emerging Technologies, 60, 102300

Ziuzina, D., Patil, S., Cullen, P.J., Keener, K.M. \& Bourke, P. (2014). Atmospheric cold plasma inactivation of Escherichia coli, Salmonella enterica serovar Typhimurium and Listeria monocytogenes inoculated on fresh produce. Food Microbiology, 42, 109-116 